\title{
New Reconstruction of Antarctic Near-Surface Temperatures: Multidecadal Trends and Reliability of Global Reanalyses*,+
}

\author{
Julien P. NiCOLAS AND DAVID H. BROMWICH \\ Polar Meteorology Group, Byrd Polar Research Center, and Atmospheric Sciences Program, Department of \\ Geography, The Ohio State University, Columbus, Ohio
}

(Manuscript received 2 December 2013, in final form 21 July 2014)

\begin{abstract}
A reconstruction of Antarctic monthly mean near-surface temperatures spanning 1958-2012 is presented. Its primary goal is to take advantage of a recently revised key temperature record from West Antarctica (Byrd) to shed further light on multidecadal temperature changes in this region. The spatial interpolation relies on a kriging technique aided by spatiotemporal temperature covariances derived from three global reanalyses [the European Centre for Medium-Range Weather Forecasts (ECMWF) Interim Re-Analysis (ERAInterim), Modern-Era Retrospective Analysis for Research and Applications (MERRA), and Climate Forecast System Reanalysis (CFSR)]. For 1958-2012, the reconstruction yields statistically significant annual warming in the Antarctic Peninsula and virtually all of West Antarctica, but no significant temperature change in East Antarctica. Importantly, the warming is of comparable magnitude both in central West Antarctica and in most of the peninsula, rather than concentrated either in one or the other region as previous reconstructions have suggested. The Transantarctic Mountains act for the temperature trends, as a clear dividing line between East and West Antarctica, reflecting the topographic constraint on warm air advection from the Amundsen Sea basin. The reconstruction also serves to highlight spurious changes in the 1979-2009 time series of the three reanalyses that reduces the reliability of their trends, illustrating a longstanding issue in high southern latitudes. The study concludes with an examination of the influence of the southern annular mode (SAM) on Antarctic temperature trends. The results herein suggest that the trend of the SAM toward its positive phase in austral summer and fall since the 1950 s has had a statistically significant cooling effect not only in East Antarctica (as already well documented) and but also (only in fall) in West Antarctica.
\end{abstract}

\section{Introduction}

Long-term changes in Antarctic near-surface air temperature constitute an important parameter affecting, directly or indirectly, the Antarctic Ice Sheet's mass balance and its contribution to sea level rise. An increase in temperature has two opposite effects for Antarctica. The first effect is surface melting, which occurs when the temperature approaches $0^{\circ} \mathrm{C}$. This can lead to mass loss directly, through meltwater runoff, or indirectly, by

\footnotetext{
* Byrd Polar Research Center Contribution Number 1445.

${ }^{+}$Supplemental information related to this paper is available at the Journals Online website: http://dx.doi.org/10.1175/JCLI-D-13-00733.s1.

Corresponding author address: Julien Nicolas, Byrd Polar Research Center, The Ohio State University, 1090 Carmack Rd., Columbus, $\mathrm{OH} 43210$

E-mail: nicolas.7@osu.edu
}

contributing to ice-shelf break-up, subsequent glacier acceleration, and ultimately increasing ice discharge into the ocean. The first mechanism (meltwater runoff), prominent in Greenland, is still relatively limited in Antarctica (Tedesco et al. 2007; Kuipers Munneke et al. 2012) and is expected to remain largely so in the upcoming decades (Krinner et al. 2007; Ligtenberg et al. 2013). The second mechanism (ice-shelf weakening) is potentially far more significant given the buttressing effect of the large coastal ice shelves for the structurally unstable West Antarctic Ice Sheet (Joughin and Alley 2011). Melt ponding as a precursor of ice-shelf break-up has already been observed in the Antarctic Peninsula (Rignot et al. 2004; Scambos et al. 2004; Pritchard and Vaughan 2007) but seems to have played a minor role in the recent acceleration of glaciers in the Amundsen Sea sector of West Antarctica, linked primarily to warm ocean water and sub-ice-shelf melting (Jacobs et al. 2011; Pritchard et al. 2012; Depoorter et al. 2013; Stanton et al. 2013). 
The second effect of higher near-surface temperature results from the positive exponential relationship between atmospheric moisture and temperature, and translates into greater snowfall over Antarctica and thus the removal of water from the ocean. This phenomenon accounts for the negative sea level contribution of Antarctica often projected for the twenty-first century (Gregory and Huybrechts 2006; Bengtsson et al. 2011; Ligtenberg et al. 2013). However, the magnitude of the precipitationtemperature sensitivity varies between studies and depends in part on how well temperature changes near the surface reflect those occurring aloft. Furthermore, recent studies suggest that this future negative impact on sea level may be offset by dynamical ice changes (Bindschadler et al. 2013; Church et al. 2013), similar to what has already been observed in recent years (Shepherd et al. 2012).

Given the large interannual and decadal variability characteristic of Antarctic climate, placing recent temperature changes in a longer-term context is important to determine their significance and the role of natural variability versus anthropogenic forcing (Schneider et al. 2006; Gillett et al. 2008; Goosse et al. 2012; Abram et al. 2013; Steig et al. 2013; Thomas et al. 2013). Data sparsity is the primary challenge that one faces when trying to piece together the temperature history of Antarctica. Direct meteorological observations in the region began for the most part with the 1957-58 International Geophysical Year (IGY). Poleward of $60^{\circ} \mathrm{S}$, a mere 15 research stations have temperature records extending from the IGY (or immediately thereafter) to the present. Despite their small number, these records have been used to reveal and investigate important aspects of Antarctic climate change (e.g., Thompson and Solomon 2002; Vaughan et al. 2003; Turner et al. 2005; Marshall et al. 2013; Richard et al. 2013). The main limitation of these investigations is that 1 ) they rely on stations mostly located on the coast, thus providing little insight into the vast Antarctic interior, and 2) they largely leave aside West Antarctica, owing to the lack of long-term continuous instrumental records in the region (here and throughout the paper, West Antarctica is meant as separate from the Antarctic Peninsula; see Fig. 1). Global atmospheric reanalyses, which combine various types of meteorological observations with the fields from a weather forecasting model, represent a promising alternative for reconstructing the climate of Antarctica from the past decades. Unfortunately, despite significant progress made in recent reanalyses, their trends have proven unreliable in high southern latitudes (Hines et al. 2000; Marshall 2002; Bromwich and Fogt 2004; Bromwich et al. 2007, 2011).
The spatial homogeneity of Antarctic monthly mean temperature anomalies over hundreds of kilometers (Comiso 2000; King and Comiso 2003) has fortunately made it possible to exploit the sparse observation network to reconstruct Antarctic temperatures from the late 1950s onward. Since 2007, several temperature reconstructions have been published, based on various spatial interpolation techniques. The latter include natural neighbor interpolation modulated by a correlation length scale parameter (Chapman and Walsh 2007), a kriging-based method with a kriging field derived from global reanalysis temperature data (Monaghan et al. 2008), and principal component analysis applied to satellite infrared skin temperature measurements (Steig et al. 2009; O'Donnell et al. 2011). Some of these reconstructions have been key in drawing attention to the warming of West Antarctica since the IGY (Steig et al. 2009; Schneider et al. 2012a). However, differences in the magnitude, pattern, and seasonality of this warming among the reconstructions still undermine our current understanding of the phenomenon.

These discrepancies can be attributed, in part, to different uses of the temperature observations from Byrd (site 14 in Fig. 1). This dataset fills a vast data void between the western Ross Ice Shelf, South Pole, and the northern Antarctic Peninsula, but it is unfortunately only partially complete. Repeated efforts have been made to fill in the temporal gaps of the Byrd record using various ancillary datasets (Shuman and Stearns 2001; Reusch and Alley 2004; Monaghan et al. 2008; Küttel et al. 2012; Bromwich et al. 2013). The importance of the Byrd record for Antarctic temperature reconstructions is highlighted in Monaghan et al. (2008) by the marked sensitivity of their results to the inclusion of Byrd in the spatial interpolation. This comes from the fact that temperature variability in central West Antarctica is poorly captured by the surrounding long-term temperature records (Bromwich et al. 2013), which in turn stems from the distinct climatic nature of West Antarctica compared to the rest of the continent (e.g., Guo et al. 2004; Bromwich et al. 2004; Bindschadler 2006). The infilling technique originally used by Monaghan et al. (2008) was revised in 2010 to take advantage of temperature data from automatic weather stations closer to Byrd than the manned stations used originally (Küttel et al. 2012). This revision had a significant impact on the temperature trends reported for West Antarctica (from insignificant cooling to highly significant warming), which were then in better agreement with those found by Steig et al. (2009) (see Schneider et al. 2012a).

In an effort to ascertain long-term temperature changes in West Antarctica, Bromwich et al. $(2013,2014)$ recently carried out a comprehensive reexamination of the Byrd 


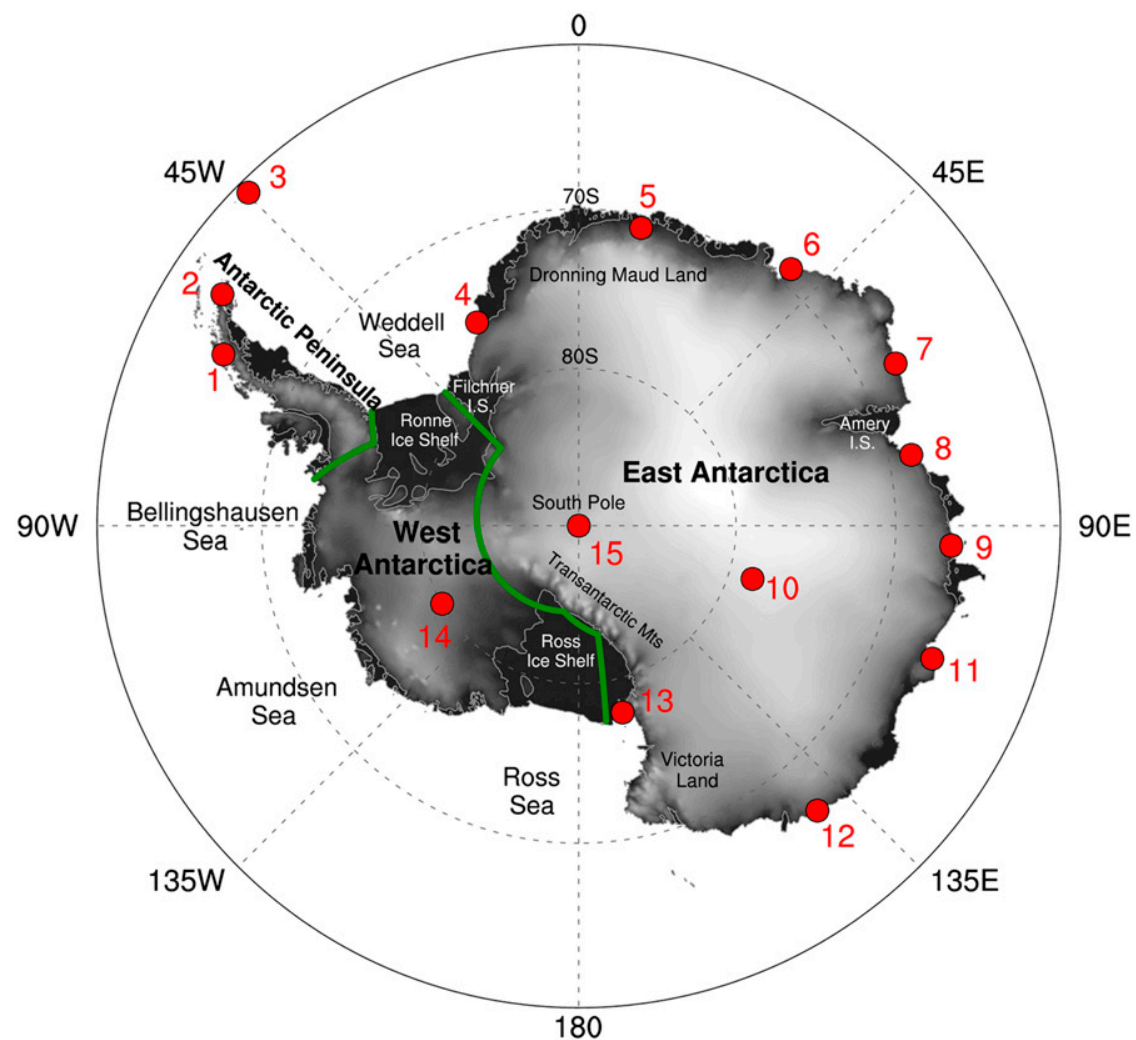

FIG. 1. Map of Antarctica showing the locations of the 15 stations used in the temperature reconstruction (filled red circles). The station names and coordinates are listed in Table 2. The thick green lines outline the boundaries of the three main Antarctic regions (boldface). Note that, in this map and throughout the paper, West Antarctica does not include the Antarctic Peninsula. The gray shades represent the topography from near sea level (darker gray) to $>4000 \mathrm{~m}$ above mean sea level.

temperature record from its start in 1957 to the present time. This work resulted in more temporally consistent observations and more reliable infilling of the data gaps. Here, our purpose is to present the results from a new reconstruction of Antarctic temperatures. The primary motivations for adding a new dataset to those already existing came from the importance of the Byrd record mentioned above; the fact that none of the previous reconstructions include its recent revisions; the current lack of consensus on temperature changes in West Antarctica; and finally the multiple examples of ongoing rapid climate change in the very same region.

The paper is organized as follows. Data and methods are described in section 2. The discussion of the results (section 3) begins with an overview of the skill of our reconstruction (section 3a), followed by a description of the temperature variability and trends that can be inferred from it (sections $3 \mathrm{~b}-3 \mathrm{e}$ ). The reconstruction is then used to shed light on two issues: the reliability of the temperature trends in global reanalyses (section $4 \mathrm{a}$ ) and the contribution of the southern annular mode (SAM) to Antarctic temperature changes since the late 1950 s (section 4b). A summary and conclusions are given in section 5. The following notation will be used hereafter to refer to the three reconstructions most frequently cited: S09 for Steig et al. (2009); M10 for the reconstruction of Monaghan et al. (2008), revised in 2010; and O11 for O'Donnell et al. (2011).

\section{Data and method}

\section{a. Temperature datasets}

A list of all the datasets used in this study along with their reference(s) and website is given in Table 1 . The near-surface temperature records that are spatially interpolated in our reconstruction come from 15 Antarctic stations and are available almost continuously from around the IGY onward. The 15 stations are listed in Table 2 and their locations are shown in Fig. 1. Their respective monthly mean temperature time series are obtained from the Reference Antarctic Data for Environmental Research 
TABLE 1. List of datasets used in this study.

\begin{tabular}{|c|c|c|}
\hline Dataset & References & Website \\
\hline ERA-Interim & Dee et al. (2011) & data-portal.ecmwf.int/data/d/interim_full_moda/ \\
\hline MERRA & Rienecker et al. (2011) & disc.sci.gsfc.nasa.gov/daac-bin/DataHoldings.pl \\
\hline CFSR & Saha et al. (2010) & rda.ucar.edu/datasets/ds093.2/ \\
\hline READER observations & Turner et al. (2004) & www.antarctica.ac.uk/met/READER/ \\
\hline$M C D W^{\mathrm{a}}$ observations & - & www.ncdc.noaa.gov/IPS/mcdw/mcdw.html \\
\hline Byrd temp record & Bromwich et al. $(2013,2014)$ & polarmet.osu.edu/Byrd_recon/ \\
\hline S09 temp reconstruction & Steig et al. (2009) & $\begin{array}{l}\text { www.usap-data.org/entry/NSF-ANT04-40414/ } \\
\text { 2009-09-12_11-10-10/ }\end{array}$ \\
\hline M10 temp reconstruction ${ }^{\mathrm{b}}$ & Monaghan et al. (2008), Küttel et al. (2012) & Personal communication \\
\hline O11 temp reconstruction ${ }^{c}$ & O'Donnell et al. (2011) & www.climateaudit.info/data/odonnell/ \\
\hline SAM index & Marshall (2003) & www.antarctica.ac.uk/met/gjma/sam.html \\
\hline
\end{tabular}

${ }^{a}$ Monthly Climatic Data for the World.

$\mathrm{b}$ This dataset refers to the reconstruction of Monaghan et al. (2008) subsequently revised in 2010.

${ }^{c}$ A version of this dataset is also available, along with our temperature reconstructions, at polarmet.osu.edu/Antarctic_recon/.

(READER) project (Turner et al. 2004), except for Byrd, for which we used the reconstructed record from Bromwich et al. (2013, 2014). For the few instances of missing data in the 14 READER datasets, we useif they exist-the monthly temperature reports published in the National Climatic Data Center's Monthly Climatic Data for the World (MCDW). The remainder of the data gaps is treated as described at the end of section $2 b$.

To determine the spatiotemporal covariances (kriging fields) required in the spatial interpolation, we rely on gridded monthly mean 2-m temperature $\left(T_{2 \mathrm{~m}}\right)$ data from three global reanalyses: the European Centre for Medium-Range Weather Forecasts (ECMWF) Interim Re-Analysis (ERA-Interim, herein ERAI; Dee et al. 2011); the National Aeronautic and Space Administration (NASA) Modern-Era Retrospective Analysis for Research and Applications (MERRA; Rienecker et al. 2011); and the National Centers for Environmental Prediction (NCEP) Climate Forecast System Reanalysis (CFSR; Saha et al. 2010). When evaluated in high southern latitudes, the three reanalyses have shown significantly greater reliability than earlier-generation reanalyses (Bromwich et al. 2011, 2013; Bracegirdle and Marshall 2012; Bracegirdle 2013; Screen and Simmonds 2012). This improvement comes mainly as a result of improved model physics, more advanced bias correction and data assimilation techniques, and higher horizontal and vertical model resolution.

For ERAI, we use two separate $T_{2 \mathrm{~m}}$ datasets available on the ECMWF data server: one originates from the forecast fields (ERAI-f), the other from the analysis fields (ERAI-a). The former is a product of 6-h model forecasts and is interpolated from the reanalysis model lowest vertical level. The latter is generated by the surface analysis (Simmons et al. 2010; Dee et al. 2011) —a distinct feature of ECMWF reanalyses-whereby screen-level temperature observations are combined with the forecast $T_{2 \mathrm{~m}}$ field via optimal interpolation. This greater observational constraint, however, becomes a disadvantage in our case as it is responsible for artifacts in the time series caused by the changing availability of observations.

The three reanalyses range, in horizontal resolution, from $\sim 80 \mathrm{~km}$ for ERAI to $\sim 55 \mathrm{~km}$ in MERRA to $\sim 38 \mathrm{~km}$ in CFSR. For our purpose, they are bilinearly interpolated to a common $60 \times 60 \mathrm{~km}^{2}$ Cartesian grid. They all start in January 1979 and, since their initial release, have been updated up to the most recent months. However, because access to the monthly data from CFSR is currently only possible through December 2009, we restrict all reanalysis data to $1979-2009$.

TABLE 2. List of the 15 research stations whose temperature records are used in our reconstruction. The numbers in the first column refer to the locations shown in Fig. 1.

\begin{tabular}{rllll}
\hline \hline No. & \multicolumn{1}{c}{ Station name } & Lat. & Lon. & Start \\
\hline & & $\left({ }^{\circ} \mathrm{N}\right)$ & $\left({ }^{\circ} \mathrm{E}\right)$ & Year \\
1 & Faraday/Vernadsky & -65.2 & -64.3 & 1950 \\
2 & Esperanza* & -63.4 & -57.0 & 1945 \\
3 & Orcadas & -60.7 & -44.7 & 1903 \\
4 & Halley & -75.6 & -26.6 & 1957 \\
5 & Novolazarevskaya & -70.8 & 11.8 & 1961 \\
6 & Syowa & -69.0 & 39.6 & 1957 \\
7 & Mawson & -67.6 & 62.9 & 1954 \\
8 & Davis & -68.6 & 78.0 & 1957 \\
9 & Mirny & -66.6 & 93.0 & 1956 \\
10 & Vostok & -78.5 & 106.8 & 1958 \\
11 & Casey & -66.3 & 110.5 & 1959 \\
12 & Dumont d'Urville & -66.7 & 140.0 & 1956 \\
13 & Scott Base & -77.9 & 166.8 & 1957 \\
14 & Byrd & -80.0 & -119.5 & 1957 \\
15 & Amundsen-Scott & -90.0 & 0.0 & 1957 \\
\hline
\end{tabular}

* This station replaces Bellingshausen used by M10. 
We compare our reconstructed temperatures with three other Antarctic temperature reconstructions, namely the M10 reconstruction; the main S09 reconstruction, based on original (nondetrended) Advanced Very High Resolution Radiometer (AVHRR) data; and the regularizedleast squares (RLS) reconstruction of O11.

\section{b. Spatial interpolation method}

Our reconstruction aims to produce estimates of monthly mean temperature anomalies (i.e., departures from the mean annual cycle) for all Antarctica from 1958 to 2012 based on the 15 station records mentioned above. The interpolation method builds upon the kriging technique employed by M10 and originally developed to reconstruct Antarctic snowfall (Monaghan et al. 2006). Here, we modify the original approach (primarily regarding the definition of the kriging weights) to more fully exploit some of the properties of ordinary kriging (Cressie 1993; Olea 1999). A brief description of the two main equations of the interpolation algorithm is provided below.

For a certain month $t$, the temperature anomaly $\Delta \hat{y}$ predicted at a certain location or grid point $\mathbf{x}$ is estimated as the linear combination of the temperature anomalies $\Delta y_{k}, k=1, \ldots, N$, observed at the $N$ stations considered in the interpolation (here, $N=15$ ):

$$
\Delta \hat{y}(\mathbf{x}, t)=\sum_{k=1}^{N} \eta_{k}(\mathbf{x}) \lambda_{k}(\mathbf{x}) \Delta y_{k}(t) .
$$

In this equation, $\lambda_{k}(\mathbf{x})$ represents the weight $(\geq 0)$ assigned to the $k$ th station at a certain location $\mathbf{x}$ on our grid; $\eta_{k}(\mathbf{x})$ is either 1 or -1 depending on the sign of the temperature correlation between the $k$ th station and location $\mathbf{x}$. To account for spatial differences in variance (typically higher in the Antarctic interior and lower near the coast), the temperature observations are normalized by their respective standard deviations during 19792009. Thus, Eq. (1) produces a normalized value, which is then multiplied by the standard deviation of the reanalysis data at location $\mathbf{x}$ to yield the final temperature anomaly. The procedure is carried out separately for each month and repeated with each reanalysis dataset.

The kriging weights $(\lambda)$ characterize the spatial representativeness (or footprint) of the observations. These footprints are determined from the $T_{2 \mathrm{~m}}$ field of the four global reanalyses mentioned above and defined as the squared Pearson's correlation coefficients $\left(r^{2}\right)$ between the model temperature at the grid point closest to the observations and the model temperature at every other Antarctic grid point. The $r^{2}$ coefficients are calculated for 1979-2009 (our calibration period) from linearly detrended reanalysis data. We denote $r_{k}^{2}(\mathbf{x})$ the spatial footprint associated with the $k$ th observation.
One important aspect of kriging introduced here and absent from M10 is the use of optimized weighting coefficients. In M10, the contributions of all observations in the interpolation are considered, regardless of multicollinearity between some of the records and thus increasing the risk of overfitting. This problem is fortunately specifically addressed in ordinary kriging by requiring the minimization of the estimation error (Cressie 1993; Olea 1999). This condition is satisfied by the following matrix equation defining the optimal weights, noted $\boldsymbol{\lambda}=\left(\lambda_{1}, \ldots, \lambda_{N}\right)^{\mathrm{T}}$ :

$$
\underbrace{\left[\begin{array}{cc}
\mathbf{A} & \mathbf{1} \\
\mathbf{1}^{\mathrm{T}} & 0
\end{array}\right]}_{\mathbf{A}^{*}} \underbrace{\left[\begin{array}{c}
\boldsymbol{\lambda} \\
\alpha
\end{array}\right]}_{\boldsymbol{\lambda}^{*}}=\underbrace{\left[\begin{array}{c}
\mathbf{b} \\
1
\end{array}\right]}_{\mathbf{b}^{*}} .
$$

Here, $\mathbf{A}$ is an $N \times N$ symmetric matrix describing the covariances between observations; $\mathbf{1}$ is a column vector of $N$ ones; $\mathbf{b}$ is an $N$-element column vector containing the spatial footprints evaluated at location $\mathbf{x}$ where the temperature anomaly must be estimated; $\mathbf{A}^{*}, \boldsymbol{\lambda}^{*}$, and $\mathbf{b}^{*}$ are identical to $\mathbf{A}, \boldsymbol{\lambda}$, and $\mathbf{b}$, respectively, except for one additional element in each dimension; and the superscript $\mathrm{T}$ denotes the transpose symbol. The elements of $\mathbf{A}$ and $\mathbf{b}$ are defined as

$$
\mathbf{A}_{i j}=r_{i}^{2}\left(\mathbf{x}_{j}\right) \quad \text { and } \quad \mathbf{b}_{i}=r_{i}^{2}(\mathbf{x}),
$$

with $i=1, \ldots, N$ and $j=1, \ldots, N$ ( $i$ and $j$ are interchangeable with $k$ used previously). The variable $\mathbf{x}_{j}$ denotes the location (nearest grid point) of the $j$ th observation; $\alpha$ is a parameter known as the Lagrange multiplier, required in the error minimization but without further bearing on our method. Equation (2) can be solved for $\boldsymbol{\lambda}^{*}$ (and therefore $\boldsymbol{\lambda}$ ) by inverting matrix $\mathbf{A}^{*}$. This inversion yields weighting coefficients that are normalized to one and can be supplied to Eq. (1) to predict the temperature anomaly. A more detailed description of the content of Eq. (2) is provided in appendix A.

One of the benefits of Eq. (2) is to handle the clustering of observations, that is, to assign less overall weight at nearby stations (e.g., along the coast of East Antarctica) than if these stations were considered in isolation, thereby reducing the risk of overfitting. In addition, the values predicted at the locations of the $N$ input stations are identical to the observations (kriging is an exact interpolation method; Lam 1983). A trade-off of having strong observational anchor points is that our reconstruction includes a higher level of noise in the time series than those based, for example, on mode decomposition, such as S09.

Our algorithm assumes complete temperature records for all stations. A few of them, however, do contain data gaps, even after infilling with $M C D W$ monthly reports. 
To reconstruct the temperature during the months when missing data occur, we use a different set of $\lambda$ coefficients calculated by omitting the stations (in most cases only one station) with incomplete records. This approach takes advantage of the large overlapping areas between some of the stations' spatial footprints.

\section{c. Skill statistics}

The combination of our interpolation algorithm with the four reanalysis datasets produces four reconstructions, referred to hereafter as $\mathrm{RECON}_{X}$, the subscript $X$ standing for the reanalysis used to derive the kriging weights. The respective skills of these reconstructions are assessed through comparison against the original reanalysis data and against observations from Antarctic stations not used in the spatial interpolation and obtained from READER (see the supplemental material for the list of stations). These two comparisons complement each other: reanalyses provide complete spatial and temporal coverage but are subject to model error and artifacts; observations, on the other hand, are more reliable but are unevenly distributed in space and time. We require a minimum of three complete years of data for a record to be included in the evaluation and exclude stations nearly collocated with others (in this case keeping only the one with the longer record). Most of the selected sites are concentrated in the northern Antarctic Peninsula and western Ross Sea regions. Outside of the peninsula, only three records extend back prior to 1980 .

The four reconstructions are evaluated based on fullreconstruction and verification statistics. Full-reconstruction statistics evaluate the four "main" reconstructions (those using 1979-2009 as calibration period) and exploit the longest period during which both the validation dataset (either observations or reanalysis) and the reconstruction are available simultaneously. Verification statistics are derived from additional reconstructions produced following the split calibration/verification approach previously used in a number of climate reconstruction studies (e.g., Cook et al. 1999; Mann and Rutherford 2002; Mann et al. 2005, 2008; S09) and implemented here as follows: The 1979-2009 period is divided into two 15-yr subperiods (1980-94 and 1995-2009). One subperiod is used for calibration (i.e., to determine the kriging weights and generate a new temperature reconstruction), while the remainder of the 55 years (verification period) serves for independent evaluation of the results. Each subperiod is employed successively for calibration, yielding two sets of statistics that are then averaged together.

The evaluation statistics include the Pearson's coefficient of correlation $(r)$, the root-mean-square error (RMSE), the average explained variance $\left(R^{2}\right)$, and the coefficient of efficiency (CE). Mathematical definitions of $R^{2}$ and CE can be found in appendix B (note the difference between $r^{2}$ and $R^{2}$ ). The calculation of $r$ and $R^{2}$ is based on linearly detrended time series, which in effect reduces the impact of artificial trends present in the reanalyses (cf. section 4a). No detrending is carried out in the calculation of CE since one of the purposes of this statistic is to determine the level of agreement between the mean values of the reconstruction and the validation dataset (observations or reanalysis).

\section{d. Uncertainty estimation}

Our uncertainty estimation follows a similar approach to the one employed by S09. We estimate the $95 \%$ confidence interval around the reconstructed temperatures as $\pm 2 \sigma$, with $\sigma^{2}$ representing the total unresolved variance of the reconstruction. The latter is calculated as $\sigma^{2}=\sigma_{X}^{2}\left(1-\mathrm{CE}_{X}\right)$, where $\sigma_{X}^{2}$ is the total variance of the original temperature anomalies in reanalysis $X$, and (1$\left.\mathrm{CE}_{X}\right)$ is the fractional unresolved variance of the reconstruction relative to reanalysis $X$. To account for the reconstruction error in the uncertainty of the temperature trends, we conduct (for each grid point) $n=1000$ Monte Carlo simulations whereby the temperature time series are perturbed with Gaussian white noise having a variance equal to $\sigma^{2}$. Trends are recomputed from the $n$ perturbed series and result in a trend distribution with variance $\sigma_{\mathrm{MC}}^{2}$. This variance is then added to the squared standard error of the regression coefficient $\left(\sigma_{b}^{2}\right)$ to produce an estimate of the total error of the trend: $\sigma_{b^{\prime}}=\left(\sigma_{b}^{2}+\sigma_{\mathrm{MC}}^{2}\right)^{1 / 2}$. The values of $\sigma^{2}$ and $\sigma_{\mathrm{MC}}^{2}$ are estimated separately for monthly, seasonal, and annual mean time series. The statistical significance of the trends is based on a two-tailed $t$ test. In this test, as well as in the calculation of $\sigma_{b}$, the number of degrees of freedom is adjusted for autocorrelations as in Santer et al. (2000). Throughout the paper, the error bounds of the trends represent the $95 \%$ confidence interval (i.e., $\pm 2 \sigma_{b^{\prime}}$ for our reconstruction and $\pm 2 \sigma_{b}$ for other datasets).

\section{e. SAM index and SAM-congruent trends}

The SAM (also known as the Antarctic Oscillation) is the dominant mode of atmospheric variability in the extratropical Southern Hemisphere and describes the near-zonally symmetric pattern of pressure-geopotential height anomalies of opposite signs between mid and high southern latitudes (Thompson and Wallace 2000). Our analysis of the SAM-temperature relationships (section 4b) uses the SAM index from Marshall (2003). This index is defined as the standardized mean sea level pressure differences between $40^{\circ}$ and $65^{\circ} \mathrm{S}$, based on observations from 12 stations roughly distributed along these two latitudes. Several other SAM indices exist [see Ho et al. (2012) for a review], some of which are 
TABLE 3. Overall skill statistics for the four reconstructions presented in this study with respect to original reanalysis data and independent observations. The statistics shown are the root-mean-square error (RMSE), the correlation coefficient $(r)$, the average explained variance $\left(R^{2}\right)$, and the coefficient of efficiency $(\mathrm{CE})$. These statistics are based on monthly temperature anomalies averaged across all Antarctic grid points when compared to the reanalyses, and across all available observations otherwise (in this case, the number of observations is indicated at the bottom of the column). The bottom part of the table shows performance statistics for the reanalyses relative to observations. Boldface font highlights the dataset(s) with the highest skill for each parameter.

\begin{tabular}{|c|c|c|c|c|c|c|c|c|c|}
\hline & \multicolumn{9}{|c|}{ Full reconstructions } \\
\hline & \multicolumn{3}{|c|}{ vs original reanalysis } & \multicolumn{3}{|c|}{ vs $1979-2012$ observations } & \multicolumn{3}{|c|}{ vs $1958-78$ observations } \\
\hline & RMSE & $r$ & $R^{2}$ & RMSE & $r$ & $R^{2}$ & RMSE & $r$ & $R^{2}$ \\
\hline RECON $_{\text {ERAI-a }}$ & 1.34 & 0.83 & 0.69 & 1.36 & 0.80 & 0.61 & 1.59 & 0.69 & 0.24 \\
\hline RECON $_{\text {ERAI-f }}$ & 1.31 & 0.84 & 0.70 & 1.35 & 0.80 & 0.61 & 1.53 & 0.70 & 0.32 \\
\hline RECON $_{\text {MERRA }}$ & 1.21 & 0.80 & 0.59 & 1.34 & 0.80 & 0.62 & 1.21 & 0.82 & 0.61 \\
\hline $\mathrm{RECON}_{\mathrm{CFSR}}$ & 1.24 & 0.83 & 0.69 & 1.31 & 0.82 & 0.64 & 1.21 & 0.81 & 0.61 \\
\hline \multirow[t]{4}{*}{ No. of obs } & - & - & - & 54 & 54 & 54 & 9 & 9 & 9 \\
\hline & \multicolumn{9}{|c|}{ Verification reconstructions } \\
\hline & \multicolumn{3}{|c|}{ vs original reanalysis } & \multicolumn{3}{|c|}{ vs $1979-2012$ observations } & \multicolumn{3}{|c|}{ vs $1958-78$ observations } \\
\hline & RMSE & $r$ & $\mathrm{CE}$ & RMSE & $r$ & $\mathrm{CE}$ & RMSE & $r$ & $\mathrm{CE}$ \\
\hline RECON $_{\text {ERAI-a }}$ & 1.55 & 0.74 & 0.56 & 1.46 & 0.73 & 0.53 & 1.60 & 0.68 & 0.29 \\
\hline RECON $_{\text {ERAI-f }}$ & 1.52 & 0.75 & 0.57 & 1.45 & 0.73 & 0.53 & 1.54 & 0.69 & 0.36 \\
\hline RECON $_{\text {MERRA }}$ & 1.37 & 0.72 & 0.44 & 1.40 & 0.76 & 0.57 & 1.26 & 0.79 & 0.59 \\
\hline RECON $_{\text {CFSR }}$ & 1.44 & 0.75 & 0.57 & 1.41 & 0.74 & 0.56 & 1.25 & 0.79 & 0.60 \\
\hline \multirow[t]{4}{*}{ No. of obs } & - & - & - & 52 & 52 & 52 & 9 & 9 & 9 \\
\hline & \multicolumn{9}{|c|}{ Reanalyses } \\
\hline & \multicolumn{3}{|c|}{ vs original reanalysis } & \multicolumn{3}{|c|}{ vs $1979-2012$ observations } & \multicolumn{3}{|c|}{ vs $1958-78$ observations } \\
\hline & RMSE & $r$ & $R^{2}$ & RMSE & $r$ & $R^{2}$ & RMSE & $r$ & $R^{2}$ \\
\hline ERAI-a & - & - & - & 1.07 & 0.88 & 0.69 & - & - & - \\
\hline ERAI-f & - & - & - & 1.03 & 0.89 & 0.73 & - & - & - \\
\hline MERRA & - & - & - & 1.27 & 0.84 & 0.65 & - & - & - \\
\hline CFSR & - & - & - & 1.11 & 0.88 & 0.73 & - & - & - \\
\hline No. of obs & - & - & - & 53 & 53 & 53 & - & - & - \\
\hline
\end{tabular}

based on principal component analysis of the pressuregeopotential height fields from global reanalyses, rather than latitudinal pressure differences. Following the conclusions from Ho et al. (2012), we have elected to use the Marshall SAM index for its reliability prior to 1979 (when reanalyses are conversely less reliable) and thus for its temporal consistency throughout the time span of our reconstruction. One must keep in mind, however, that this index emphasizes the zonally symmetric component of the SAM, whereas its asymmetric component, most prominent in austral winter and spring, is also known to have important climate impacts (Ding et al. 2012; Fogt et al. 2012).

We characterize the SAM-temperature relationships via least squares linear correlations and regressions, both performed on linearly detrended annual and seasonal mean time series. The SAM contribution to Antarctic temperature trends is estimated as in Thompson et al. (2000) by calculating the temperature trends that are linearly congruent with the SAM; that is, by first linearly regressing Antarctic temperatures onto the SAM index, and by then multiplying the resulting regression coefficients by the trend in the SAM index. The total error of the regression coefficient is quantified following the same Monte Carlo procedure as the one described above for the temperature trends (the SAM index being used in place of the time axis). The relative squared error of the SAM-congruent trend is then estimated as the sum of the squared relative errors of the SAM trend and the SAM-temperature regression coefficient, respectively. One important assumption behind the use and interpretation of SAM-congruent trends is that the SAM-temperature relationships observed on an interannual basis (measured with detrended time series) remain valid on a multidecadal time scale (i.e., between the original, nondetrended time series).

\section{Results}

\section{a. Evaluation of the temperature reconstructions}

\section{1) Summary OF SKILl STATISTICS}

Antarctic-averaged evaluation statistics based on monthly temperature anomalies are presented in Table 3 and assess our four reconstructions with respect to 
independent ground observations and original reanalysis data. This table is adapted from Table 3 of O11 to facilitate comparison of the results. In their table, O11 assess the skill of their own two reconstructions [RLS and eigenvector-weighted (E-W)] and of the S09 reconstruction relative to ground observations and to AVHRR clear-sky skin temperature estimates. The results of our Table 3 can be broken down as follows:

(i) The respective skills of our reconstructions are overall comparable, regardless of the statistical parameter or the dataset used for evaluation (reanalysis or observations). The only exceptions are the two ERAI-based reconstructions when evaluated against pre-1979 observations. Their lower skill can be mainly explained by poorer statistics in the Antarctic Peninsula (where most of the few pre-1979 records are located), which in turn may be related to the coarser resolution of ERAI compared to MERRA and CFSR.

(ii) All statistics combined, $\mathrm{RECON}_{\mathrm{CFSR}}$ ranks first among our four reconstructions. For this reason, it is the one primarily used for the analysis presented in the rest of the paper. Paradoxically, the temperature trends in the original CFSR data are particularly unreliable over most of Antarctica (cf. Fig. 7, discussed in section 4a). However, the detrending of the reanalysis data prior to the calculation of the kriging weights reduces the impact of this problem on our reconstruction.

(iii) Comparison of the statistics shown in our Table 3 with those published in Table 3 of O11 suggests that our reconstructions have lower skill than the RLS reconstruction of $\mathrm{O} 11$, have skill comparable to their E-W reconstruction, and have higher skill than S09. This comparison of statistics does have certain limitations. First, the predictor (AVHRR or reanalysis) and the number/locations of observations differ between the reconstructions. Second, the two methods used by $\mathrm{O} 11$ include calibration of AVHRR principal components and spatial eigenvectors against all ground observations, hence a lack of independence between reconstruction and observations; in contrast, these observations are fully independent from our reconstructions. Third, the statistics with respect to observations are averages across all stations and thus tend to reflect the skill of the reconstructions where the density of observations is greater (northern Antarctic Peninsula, western Ross Sea/Ross Ice Shelf).

(iv) The evaluation of the original reanalysis data against observations (bottom of Table 3) reveals substantially greater skill than AVHRR tempera- tures, suggesting that the reanalyses provide a more reliable predictor for the spatial interpolation. We also note that the skill of ERAI-a (which assimilates near-surface temperature observations) is slightly lower than that of ERAI-f (which does not), whereas one would expect the opposite. This paradox can be explained by the spurious impact of observations on ERAI-a time series.

\section{2) SPATIAL OVERVIEW OF SKILL STATISTICS}

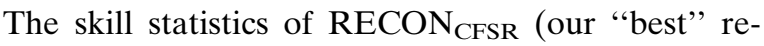
construction) at every Antarctic grid point and observation site are displayed in Fig. 2. As in Table 3, these statistics are based on monthly temperature anomalies. The general consistency between reconstruction-versusreanalysis statistics (background field in Fig. 2) and reconstruction-versus-observations statistics (color-filled circles and squares in Fig. 2) suggests that the former provide a relatively good indication of the reconstruction's skill away from observations. Nevertheless, it is perfectly possible that, in some places, the error resides in the reanalysis, not in the reconstruction.

The predominance of warm colors demonstrates the high skill of the reconstruction over most of Antarctica. The three most problematic areas are the broad Antarctic Peninsula sector, the western Ross Sea region (Victoria Land), and the interior of Dronning Maud Land. Very few grid points with negative $\mathrm{CE}$ values denote locations where the reconstruction performs less well than the climatology. When the statistics are calculated from the annual and seasonal means (cf. the supplemental material, especially Figs. S2-S5), the areas with negative CE become far more prominent. This is especially true in the Antarctic Peninsula-Ronne Ice Shelf region and more pronounced in austral summer [December-February (DJF)] and fall [March-May (MAM)].

Lower skill in the peninsula is expected given the known challenge of our spatial interpolation to resolve the effects of the complex terrain along this narrow topographic ridge. The reconstruction does, however, perform better on the western side (the side of FaradayVernadsky Station) than on the eastern side of the peninsula. In Victoria Land, the problem is again likely related to the complex topography of this region, but other factors may have contributed (e.g., the termination of the radiosonde program at the coastal Soviet station, Leningradskaya, in 1991, and its impact on the temporal consistency of the reanalysis temperatures). The interior of Dronning Maud Land is devoid of any major topographic features, so the topographic argument cannot be invoked to explain the lower skill of the reconstruction in this region (which is not fully understood). Finally, a few sites in 
(a) Full-reconstruction $r$

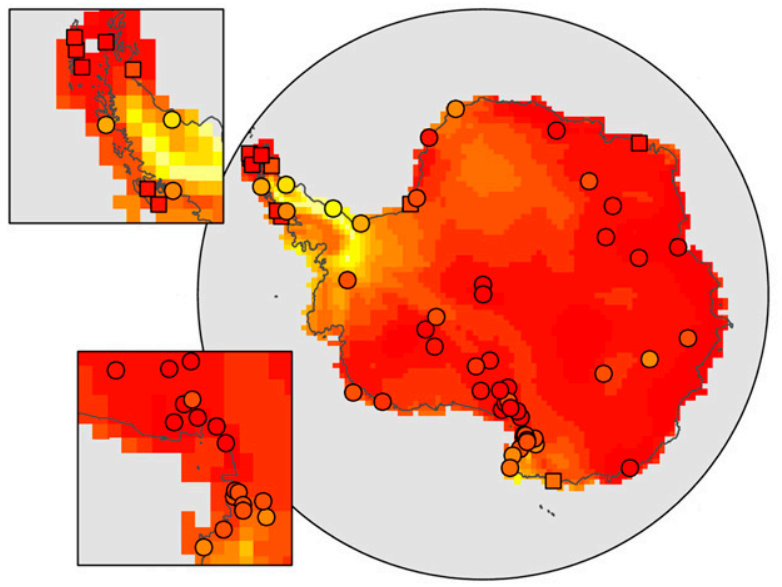

(c)

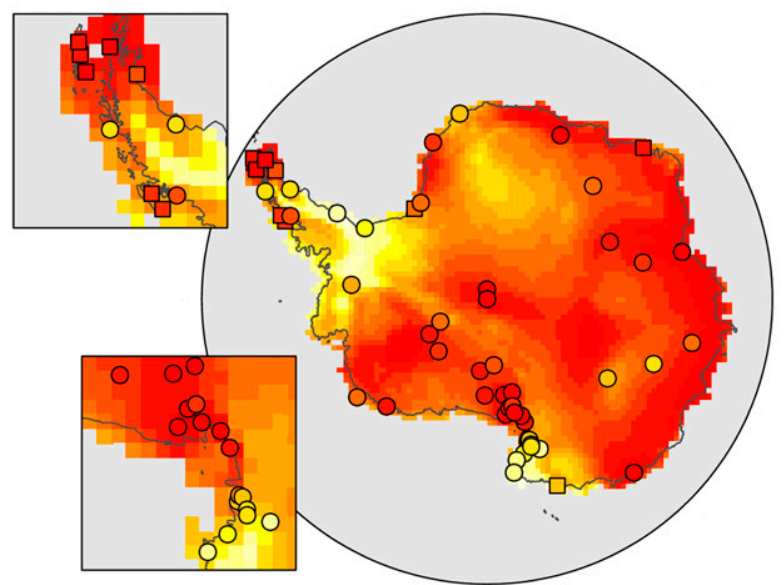

(b) Full-reconstruction $R^{2}$

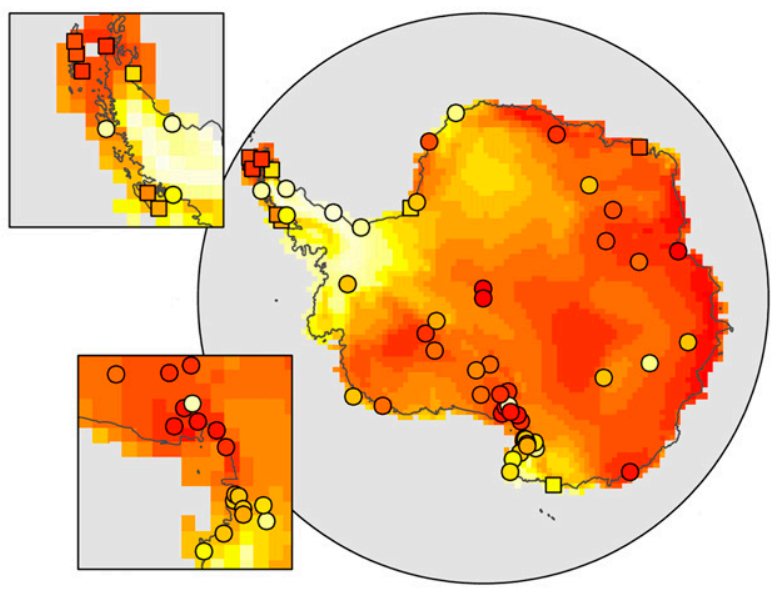

(d) Verification CE

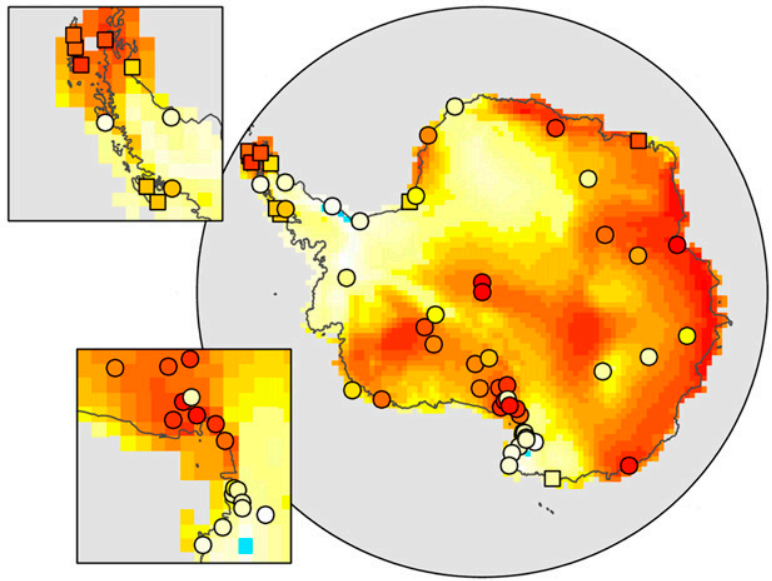

$r, R^{2}$, or CE

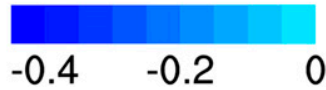

0.2

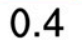

0.6

0.8

1

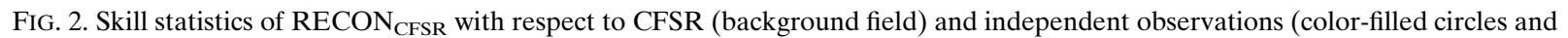
squares). The statistics are obtained by comparing, at each grid point, reconstructed and reanalysis or observed monthly temperature anomalies. Full-reconstruction statistics are with respect to reanalysis data from 1979 to 2009 and all available observations. For verification statistics, the comparison excludes reanalysis or observed data from the calibration period (see details in section $2 \mathrm{~d}$ ). Squares denote stations with temperature records starting prior to 1979; circles are used otherwise. Blue shades denote areas where the reconstruction's skill is lower than climatology.

the East Antarctic interior indicate reduced skill of the reconstruction locally. It is not certain whether the problem can be traced to the difficulty of the reanalyses to capture the strong temperature inversion that dominates the temperature regime of the Antarctic boundary layer. Fréville et al. (2014) recently showed, for example, that this is a concern in ERAI and explains the marked surface warm bias seen in this reanalysis. This issue has not yet been investigated in other reanalyses.

\section{b. Annual mean temperature time series}

The annual mean temperature time series from RECON $_{\text {CFSR }}$ spatially averaged over the three Antarctic regions are shown in Fig. 3, along with similar time series from the reconstructions of S09, M10, and 011 . In addition, Table 4 presents a quantitative comparison of the four reconstructions, which includes detrended correlations with respect to our 
(a)

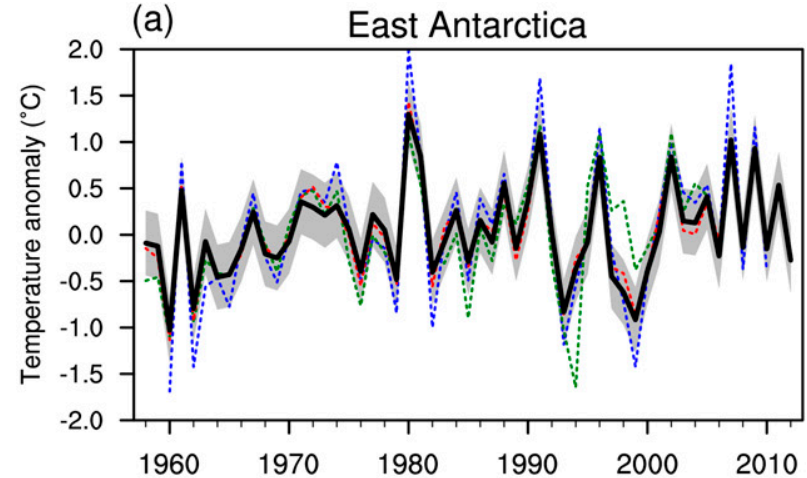

(b)

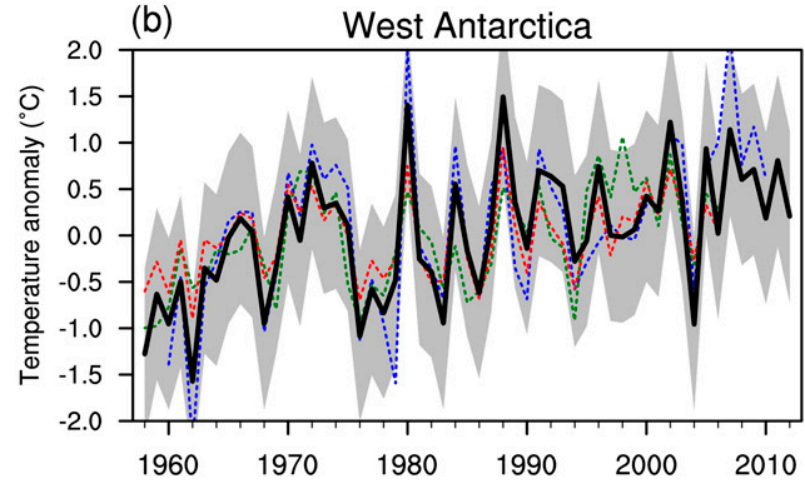

(c)

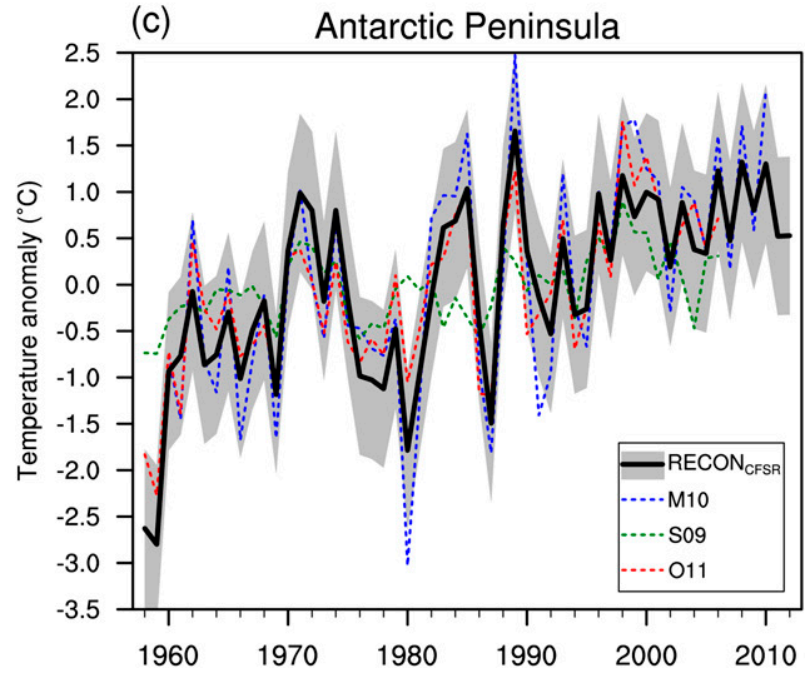

FIG. 3. Annual mean temperature times series spatially averaged over (a) East Antarctica, (b) West Antarctica, and (c) the Antarctic Peninsula (the regions' boundaries are outlined in Fig. 1). The time series are from our reconstruction $\left(\mathrm{RECON}_{\mathrm{CFSR}}\right.$; thick black line) and the reconstructions of S09 (dashed green), M10 (dashed blue), and $\mathrm{O} 11$ (dashed red) (see Table 1 for details about these datasets). The gray shading represents the $95 \%$ confidence interval of our reconstruction $( \pm 2 \sigma)$, with $\sigma^{2}$ being the unresolved variance defined in section $2 \mathrm{~d}$. All anomalies are calculated with respect to 1960-2006.
TABLE 4. Comparison statistics between our reconstruction $\left(\mathrm{RECON}_{\mathrm{CFSR}}\right)$ and the reconstructions of S09, M10, and O11 (cf. Table 1 for details about these datasets). Correlations and trends $\left({ }^{\circ} \mathrm{C}\right.$ decade $\left.^{-1}\right)$ are from annual mean temperature time series spanning 1960-2006. Correlations are based on linearly detrended time series. We do not account for the respective errors of the reconstructions, except in the calculation of the trends from RECON $_{\text {CFSR }}$. The error bounds of the trends represent the $95 \%$ confidence interval $\left( \pm 2 \sigma_{b^{\prime}}\right.$ for RECON $\mathrm{RFSR}_{\mathrm{C}}, \pm 2 \sigma_{b}$ for the other reconstructions). Boldface denotes trends statistically significant at the $95 \%$ confidence level.

\begin{tabular}{lccc}
\hline \hline & East & West & Peninsula \\
\hline \multicolumn{4}{c}{ Correlations with RECON } \\
M10 & 0.97 & 0.85 & 0.87 \\
S09 & 0.81 & 0.65 & 0.53 \\
O11 & 0.98 & 0.90 & 0.84 \\
\multicolumn{2}{c}{$1960-2006$ temperature } & trends \\
RECON & $0.04 \pm 0.12$ & $\mathbf{0 . 1 9} \pm \mathbf{0 . 1 5}$ & $\mathbf{0 . 2 9} \pm \mathbf{0 . 1 9}$ \\
M10 & $0.10 \pm 0.16$ & $\mathbf{0 . 2 0} \pm \mathbf{0 . 1 6}$ & $\mathbf{0 . 3 9} \pm \mathbf{0 . 2 2}$ \\
S09 & $0.11 \pm 0.12$ & $\mathbf{0 . 1 6} \pm \mathbf{0 . 1 0}$ & $\mathbf{0 . 1 1} \pm \mathbf{0 . 0 7}$ \\
O11 & $0.05 \pm 0.11$ & $0.08 \pm 0.09$ & $\mathbf{0 . 3 0} \pm \mathbf{0 . 1 3}$ \\
\hline
\end{tabular}

reconstruction and linear trends during 1960-2006 (period common to all datasets).

Although some differences appear clearly between the four time series in Fig. 3, they generally do not exceed the error bounds of our reconstruction. Our reconstruction correlates best with M10 and O11. The good agreement with M10 is somewhat expected given their common methodological basis. The same good agreement with $\mathrm{O} 11$ is more surprising and proves that different interpolation methods can produce very similar results over vast portions of Antarctica. The correlations with S09 are consistently lower, particularly in the peninsula. In this region, the excessively low variance of the S09 time series seen in Fig. 3c is a problem previously noted by these authors (presented as a tradeoff of their lower-order method) and further discussed by $\mathrm{O} 11$.

None of the reconstructions suggests statistically significant change in East Antarctica during 1960-2006. It is noteworthy that the trend estimates from RECON CFSR $_{\text {. }}$ and $\mathrm{O} 11$ are virtually identical and about half those of S09 and M10, although the four estimates are not statistically distinguishable from one another. In West Antarctica, O11 stand out as the only dataset with insignificant trends, an exception also noted by Bromwich et al. (2013) in their comparison of temperature reconstructions at Byrd. The other three reconstructions agree to within $0.04^{\circ} \mathrm{Cdecade}^{-1}$. The similarity of the West Antarctic trends in RECON CFSR $_{\text {and }}$ S09 despite the relatively low correlation of their time series (0.65) arises from the lower-order method used by S09. It suggests that their original work did correctly capture the trends but damped some of the higher-order temporal variations. 


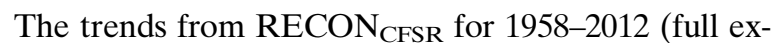
tent of the reconstruction) are shown in Table 5. For the annual temperature, the results are very similar to those obtained for 1960-2006. The positive trend in East Antarctica $\left(0.06 \pm 0.09^{\circ} \mathrm{C}\right.$ decade $\left.^{-1}\right)$ remains statistically insignificant. Our reconstruction suggests, however, that 2002-11 has been the warmest decade in East Antarctica since 1958, coming after markedly colder 1990s. West Antarctica and the Antarctic Peninsula exhibit substantially larger trends $\left(0.22 \pm 0.12^{\circ}\right.$ and $0.33 \pm$ $0.17^{\circ} \mathrm{Cdecade}^{-1}$, respectively), as expected from the mounting evidence of rapid warming of these two regions (see the next section). Note that, for West Antarctica, the magnitude and significance of the trend are somewhat contingent upon the definition of the region's boundaries given the sharp contrast in temperature change on either side of the Transantarctic Mountains (cf. Fig. 4).

\section{c. Temperature trend patterns during 1958-2012}

The spatial distribution of the annual and seasonal temperature trends derived from $\mathrm{RECON}_{\mathrm{CFSR}}$ for the 1958-2012 period are shown in Fig. 4. Kriging being an exact interpolation method, the reconstruction's trends
TABLE 5. Temperature trends $\left({ }^{\circ} \mathrm{Cdecade}^{-1}\right)$ per Antarctic region during 1958-2012 (1959-2012 for DJF) from our re-

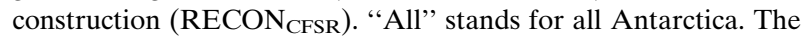
error bounds represent the $95 \%$ confidence interval $\left( \pm 2 \sigma_{b^{\prime}}\right)$. Boldface denotes trends statistically significant at this confidence level.

\begin{tabular}{lcrcc}
\hline \hline & \multicolumn{4}{c}{ Total temperature trends } \\
\cline { 2 - 5 } & \multicolumn{1}{c}{ All } & \multicolumn{1}{c}{ East } & West & Peninsula \\
\hline Annual & $\mathbf{0 . 1 1} \pm \mathbf{0 . 0 8}$ & $0.06 \pm 0.09$ & $\mathbf{0 . 2 2} \pm \mathbf{0 . 1 2}$ & $\mathbf{0 . 3 3} \pm \mathbf{0 . 1 7}$ \\
DJF & $0.07 \pm 0.15$ & $0.05 \pm 0.16$ & $0.12 \pm 0.17$ & $\mathbf{0 . 1 7} \pm \mathbf{0 . 1 3}$ \\
MAM & $0.01 \pm 0.18$ & $-0.03 \pm 0.20$ & $0.08 \pm 0.21$ & $\mathbf{0 . 3 2} \pm \mathbf{0 . 2 1}$ \\
JJA & $0.16 \pm 0.20$ & $0.09 \pm 0.23$ & $\mathbf{0 . 2 8} \pm \mathbf{0 . 2 7}$ & $\mathbf{0 . 5 8} \pm \mathbf{0 . 3 6}$ \\
SON & $\mathbf{0 . 2 0} \pm \mathbf{0 . 1 3}$ & $\mathbf{0 . 1 4} \pm \mathbf{0 . 1 3}$ & $\mathbf{0 . 3 9} \pm \mathbf{0 . 2 1}$ & $\mathbf{0 . 2 8} \pm \mathbf{0 . 2 2}$ \\
\hline
\end{tabular}

match very closely those observed at the 15 stations used in the interpolation (cf. Fig. S6 in the supplemental material).

The reconstruction reproduces the well-documented rapid warming of the Antarctic Peninsula (Vaughan et al. 2003; Turner et al. 2005). This is somewhat expected given the constraint provided by the two peninsula stations (Faraday-Vernadsky and Esperanza) used in the spatial interpolation. This result is nonetheless worth underscoring as the peninsula warming is not equally captured by all reconstructions (see the previous

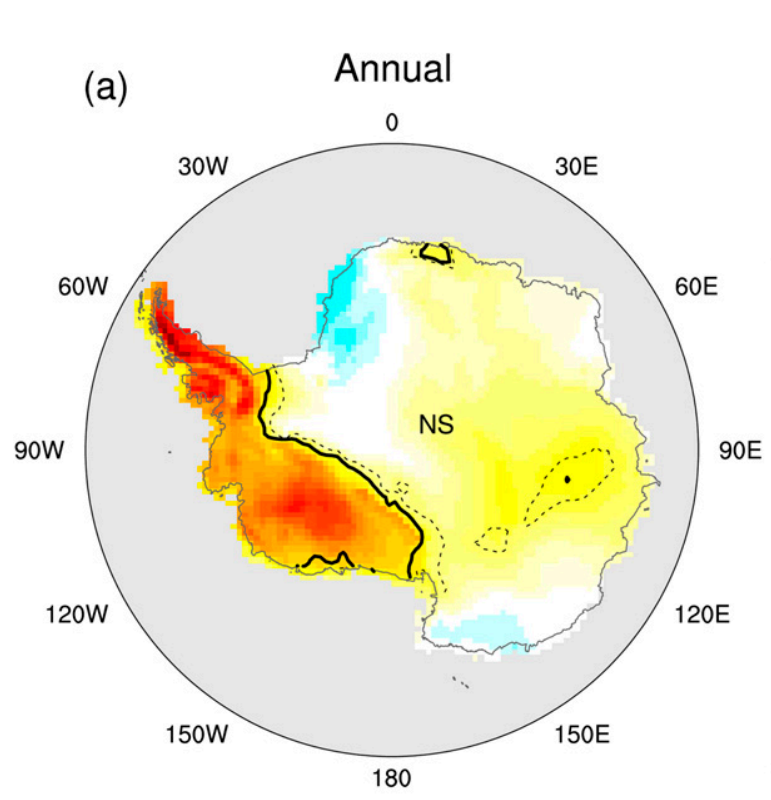

(b)

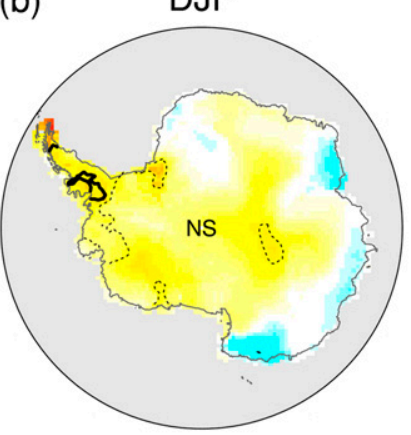

(d)

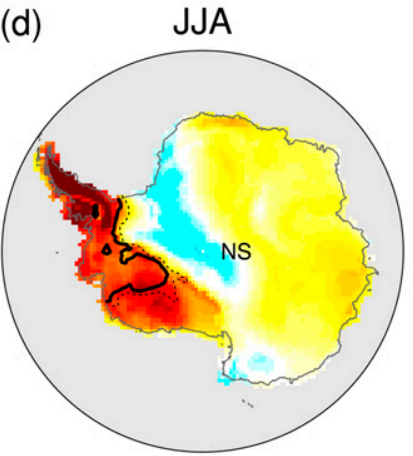

(c)

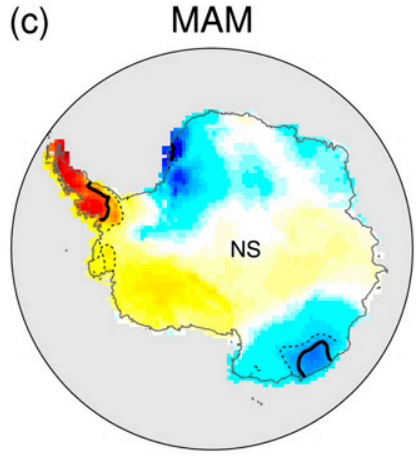

(e)

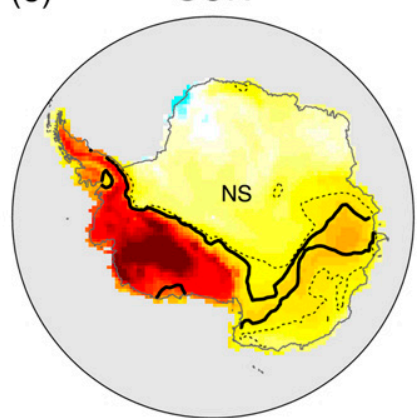

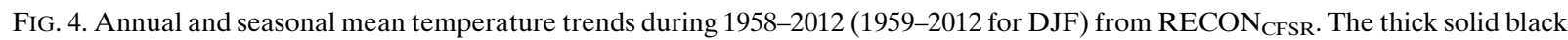
line outlines areas with trends significant at the $95 \%$ confidence level when both the regression error and the reconstruction error are accounted for. The thin dashed black line outlines the $95 \%$ significance contour when only the regression error is accounted for (i.e., assuming zero error in the reconstruction). For clarity, the notation NS highlights which side of the lines is not statistically significant. 
section). In addition, the regional and seasonal characteristics of this warming in the reconstruction are consistent with those observed (Vaughan et al. 2003; Turner et al. 2005; Marshall et al. 2006; van Lipzig et al. 2008), with a maximum in austral winter [June-August (JJA)] on the western side (although not clearly distinguishable with the color scale) and a maximum in DJF on the eastern side (in this case, statistically significant only at the very northern tip of the peninsula). As a caveat, we know from Fig. 2 that the reconstruction's skill is overall lower in the central and southern peninsula, meaning that the trends in these regions must be interpreted with caution. Yet, it is noteworthy that the strong warming depicted in the southern portion of the peninsula is consistent (at least qualitatively) with the warming seen in the temperature proxy record from the Gomez ice core (Thomas et al. 2009).

In the rest of the continent, the Transantarctic Mountains largely act as a dividing line between West Antarctic and East Antarctic temperature trends. Our reconstruction shows significant warming in the annual mean over most of West Antarctica, thereby confirming evidence from borehole measurements (Barrett et al. 2009; Orsi et al. 2012), ice-core proxy records (Steig et al. 2013; Thomas et al. 2013), and-to various degreesother near-surface and tropospheric temperature reconstructions (S09; O11; Schneider et al. 2012a; Screen and Simmonds 2012). The seasonality and magnitude of the trends in the central region largely reproduce those described by Bromwich et al. (2013) for Byrd. The strongest and most widespread warming occurs in austral spring [September-November (SON)], as highlighted by Schneider et al. (2012a). In JJA, most of West Antarctica exhibits warming trends but statistical significance is only reached in the eastern sector (facing the Bellingshausen Sea). In DJF, there is suggestion of significant warming over the Pine Island and Thwaites Glaciers only when the reconstruction error is not accounted for (cf. the method in section $2 \mathrm{~d}$ ). In other words, the uncertainty of the reconstruction in this area is currently too large to confirm this result. No significant changes are seen in MAM, the season during which West Antarctic temperatures have likely been most impacted by the high-polarity SAM that has dominated since the mid-1990s (cf. section 4b).

One further aspect of West Antarctic warming worth highlighting is the tongue-shaped pattern assumed by the trends across the central West Antarctic region. This pattern is consistent with the atmospheric signature typically associated with warm marine air intrusions (Nicolas and Bromwich 2011a), thereby reflecting the main atmospheric mechanism thought to be responsible for West Antarctic warming (Ding et al. 2011; Schneider et al. 2012a; Bromwich et al. 2013). Note that the tongue is not equally pronounced in our four reconstructions and appears most clearly in RECON ERAI-a $_{\text {and }}$ RECON $_{\text {ERAI-f }}$ (cf. Fig. S7 in the supplemental material). On the one hand, the superiority of ERAI in capturing the mean and transient atmospheric circulation in the West Antarctic sector of the Southern Ocean (Bracegirdle 2013) lends credence to the results of the two ERAI-based reconstructions. On the other hand, the reliability of this reanalysis is affected by clear evidence of nonstationarity in its temperature over the Ross Ice Shelf (cf. Fig. 8).

East Antarctica displays smaller regions of statistically significant trends. The largest patches of significant warming occur in SON and are primarily concentrated in the $90^{\circ} \mathrm{E}-180^{\circ}$ quadrant. Cooling, on the other hand, is more widespread in MAM and most pronounced at the western $\left(30^{\circ} \mathrm{W}-0^{\circ}\right)$ and eastern $\left(120^{\circ}-170^{\circ} \mathrm{E}\right)$ edges of East Antarctica. These regional coolings are likely related to atmospheric circulation changes that have promoted offshore (cold) tropospheric flow over these areas (Turner et al. 2009; Marshall et al. 2013). Other regional features are also worth noting. For example, the transition from negative to positive trends near the Greenwich meridian in the annual mean is consistent with the temperature changes seen in several borehole records from the area (Muto et al. 2011). The plateau-versuscoast contrast in DJF is consistent with the more negative impact of a stronger SAM on temperatures in coastal, katabatic-prone areas of Antarctica (Van den Broeke and van Lipzig 2004). Finally, the more pronounced warming in the $80^{\circ}-100^{\circ} \mathrm{E}$ sector is consistent with the temperature signal seen in the coastal borehole record analyzed by Roberts et al. (2013).

\section{d. Comparison with trend patterns from other reconstructions}

Some similarities and differences between our reconstruction and those from S09, M10, and O11 have already been pointed out above in the discussion of the annual mean temperature time series (section $3 b$ ). The comparison is extended here to the seasonal trend patterns calculated for 1960-2006 (period common to all datasets), shown in Fig. 5. Four points can be drawn from this comparison:

1) In DJF, the strong warming present in M10 over a large fraction of West Antarctica is not found in any other reconstruction. This can be explained by the warm bias initially present in the temperature observations from Byrd and due to a calibration error. This bias has since been corrected in the Byrd record investigated by Bromwich et al. (2013) and used in our reconstruction. 

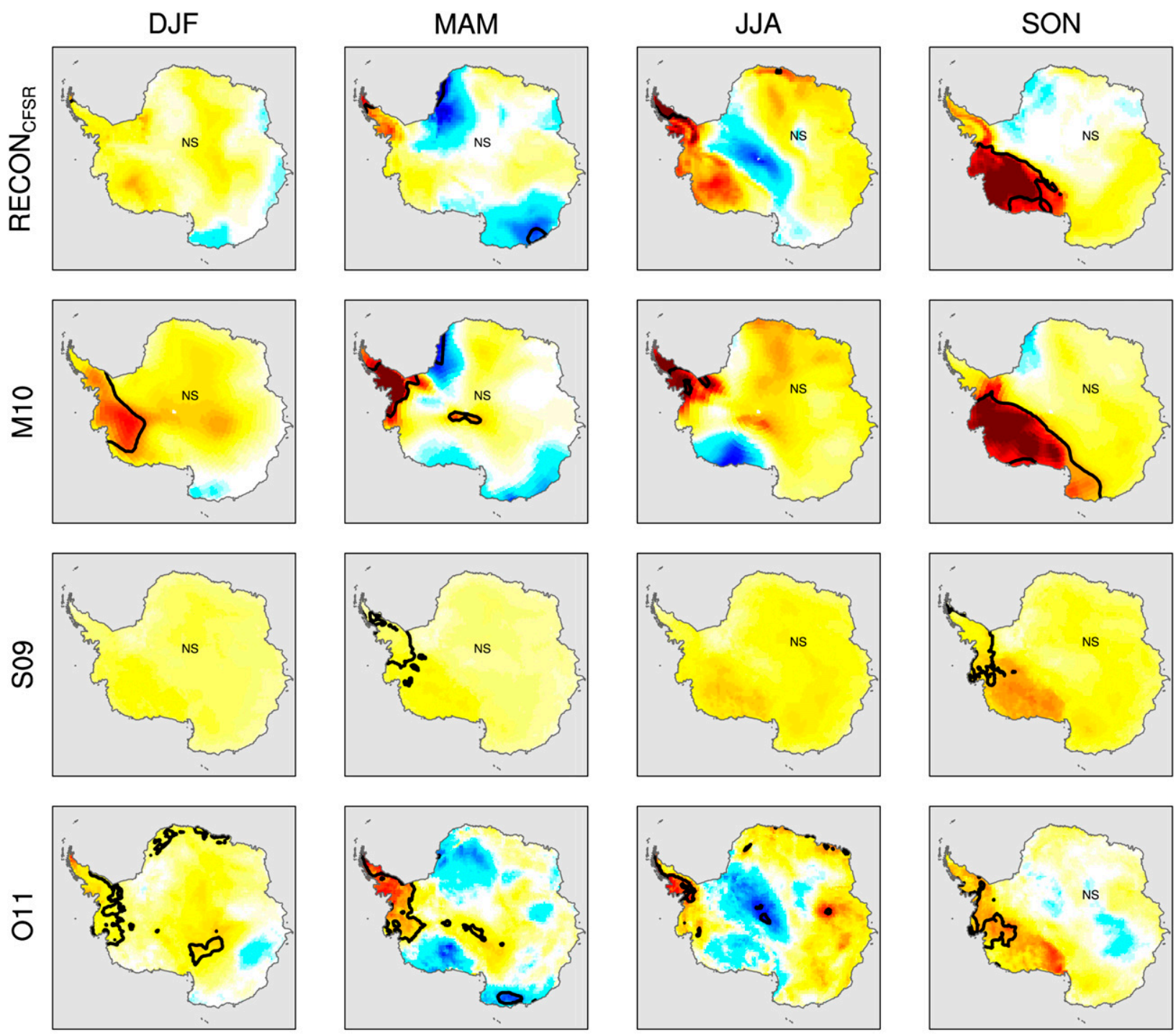

\section{0-2006 temperature trends $\left({ }^{\circ} \mathrm{C} / \mathrm{decade}\right)$}

\section{$\begin{array}{llllllllllll}-0.5 & -0.4 & -0.3 & -0.2 & -0.1 & 0 & 0.1 & 0.2 & 0.3 & 0.4 & 0.5 & 0.6\end{array}$}

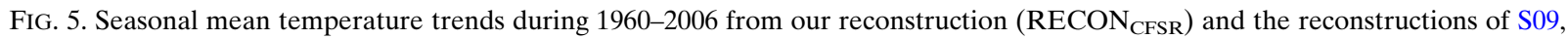

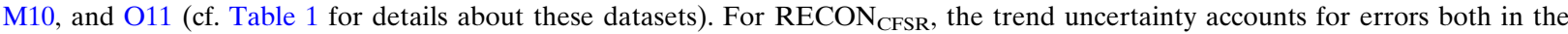
regression and in the reconstruction. For S09, M10, and O11, only the regression error is accounted for. The thick black line outlines areas with trends significant at the $95 \%$ confidence level; NS highlights which side of the line is not statistically significant.

2) In JJA, the cooling over the western side of West Antarctica depicted by M10 and O11 is in contrast with the warming seen in both our reconstruction and S09. Long-term cooling in this sector happens to be inconsistent with the changes in the atmospheric circulation since 1979 described by Ding et al. (2011), namely the trend toward higher geopotential heights (anticyclonic anomalies) over the Amundsen Sea, responsible for steering warmer air toward western West Antarctica.
3) In SON, the four reconstructions agree in showing both the strongest seasonal warming in West Antarctica and a clear contrast between West and East Antarctica. However, our reconstruction and M10 do suggest stronger warming than S09 and O11.

4) The greater homogeneity of the trend patterns in S09 in all seasons is due to the choice of a lower-order reconstruction method (i.e., use of a small number of principal components), intended to filter the noise in the temperature time series. 

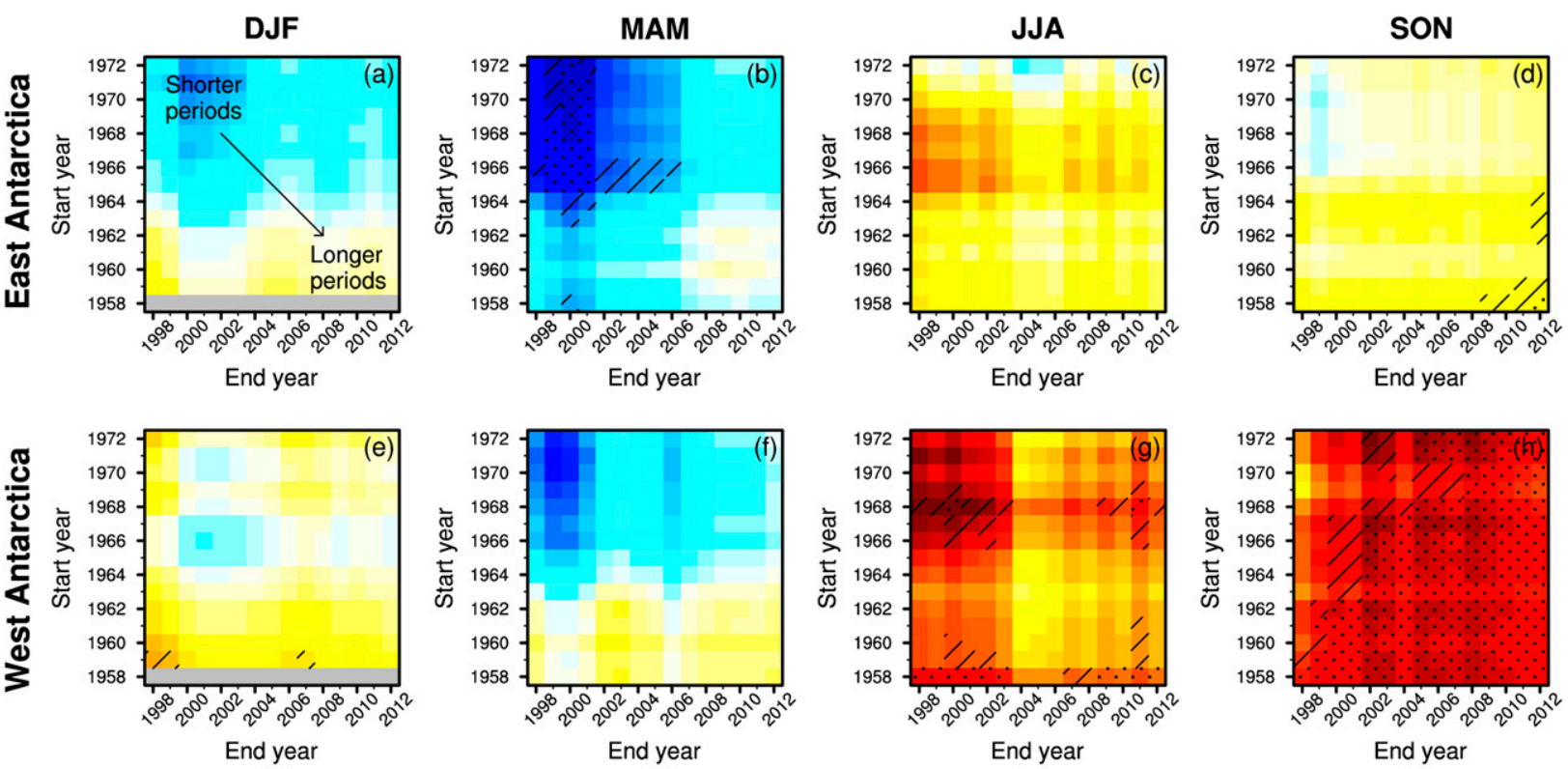

Temperature trends $\left({ }^{\circ} \mathrm{C}\right.$ decade $\left.{ }^{-1}\right)$

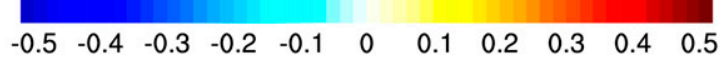

FIG. 6. Temperature trends calculated for various time periods starting within the first $15 \mathrm{yr}$ ( $y$ axis) and ending within the last $15 \mathrm{yr}$

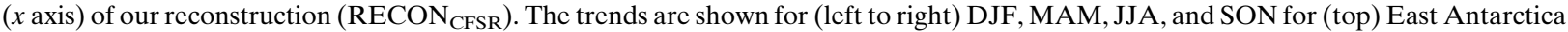
and (bottom) West Antarctica. DJF trends are only from 1959 onward. Hatching and stippling indicate trends statistically significant at the $90 \%$ and $95 \%$ levels (respectively). In both cases, the trend uncertainty accounts both for the error of the regression coefficient and for the reconstruction error.

\section{e. Sensitivity of the temperature trends to the time period}

Our main diagnostic tool for long-term temperature change (least squares linear regression) is known to be sensitive to the start and end years of the calculation period (e.g., Chapman and Walsh 2007; Monaghan et al. 2008; O11). Figure 6 is intended as a means to assess this sensitivity and thus the robustness of our results. It shows, for East and West Antarctica and for each season, the trends calculated for various time periods starting within the first $15 \mathrm{yr}$ and ending within the last $15 \mathrm{yr}$ of our reconstruction. The figure displays both the $90 \%$ and $95 \%$ significance levels to indicate whether/how the statistical significance of the trends progresses with time.

The West Antarctic warming in SON is confirmed as one of the most robust climate trend in Antarctica (Fig. 6h). There is no such equivalent in East Antarctica during the same season and the only trend with statistical significance above the $95 \%$ level is for 1958-2012 (Fig. 6d). Similarly, the significance of the JJA warming in West Antarctica is quite sensitive to the calculation period (Fig. 6g). In MAM, the marked cooling that occurred in East and West Antarctica between the late 1960s-early 1970s and late 1990s-early 2000s (shorter periods of our ensemble) is absent from the more extended periods (Figs. 6b,f). It is worth noting that this cooling was concurrent with relatively strong warming in the next season (JJA) both in West and (to a lesser extent) East Antarctica, although, to our knowledge, no linkage between the two phenomena has been established.

\section{Applications of the temperature reconstruction \\ a. Reliability of Antarctic temperature trends in global reanalyses}

The need for Antarctic temperature reconstructions came in part from the unreliability of multidecadal trends in global reanalyses. The problem has been identified (to various degrees) in the three reanalyses used here and in atmospheric fields such as precipitation, evaporation/ sublimation, and precipitable water (Bromwich et al. 2011; Cullather and Bosilovich 2011; Nicolas and Bromwich 2011b). Little has been done, however, to investigate the quality of Antarctic temperature trends in these recent reanalyses. Thus far, evaluations of Antarctic temperatures have been mainly restricted to comparisons with respect to observations from the limited station network and have primarily relied on bias and correlation analysis (Bracegirdle and Marshall 2012; Screen and 

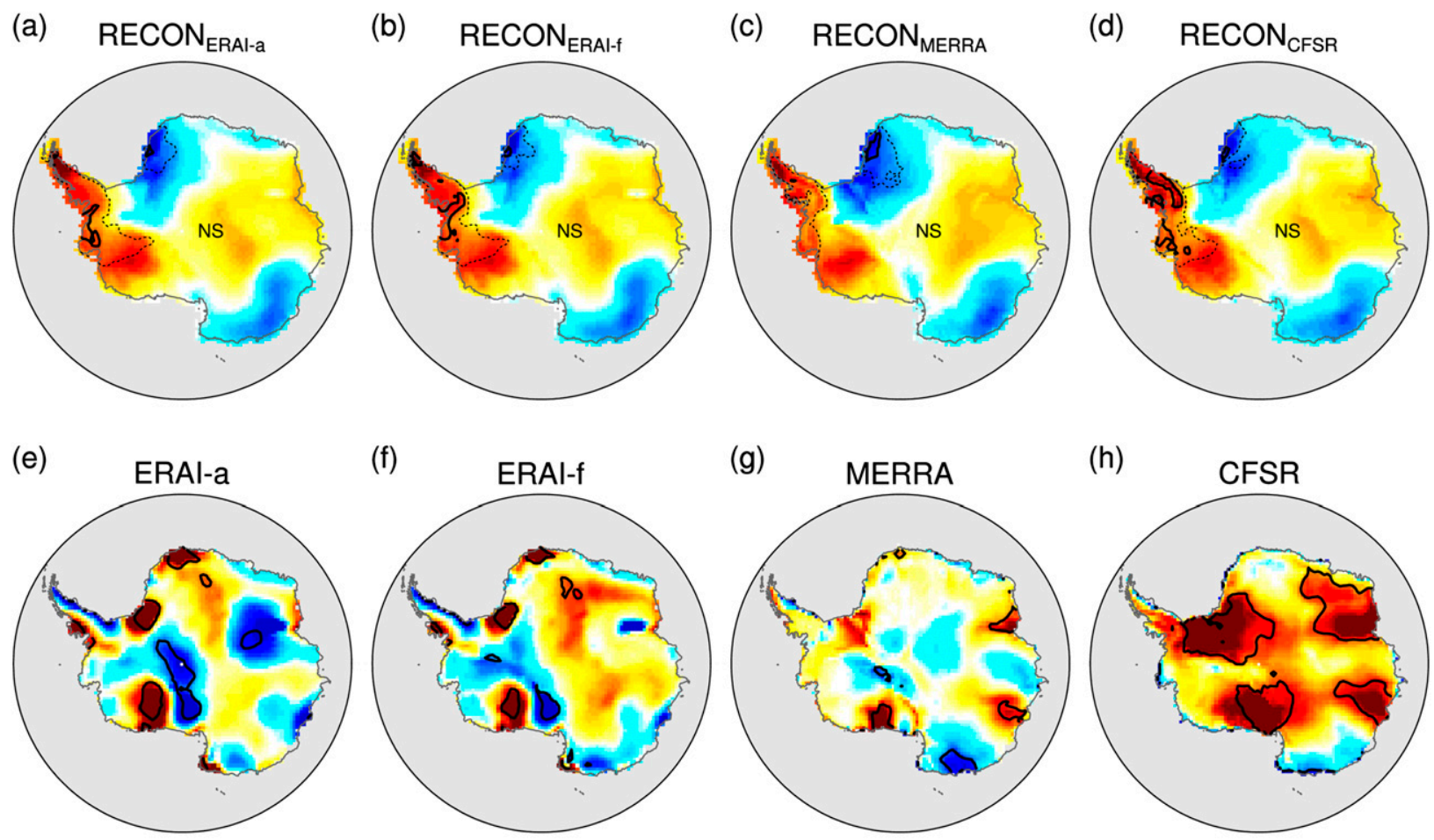

1979-2009 temperature trends $\left({ }^{\circ} \mathrm{C} / \mathrm{decade}\right)$
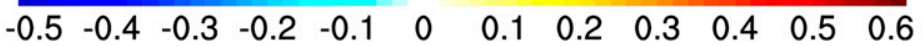

FIG. 7. Annual mean temperature trends during 1979-2009 based on (a)-(d) our four temperature reconstructions (the subscript denotes the reanalysis used to derive the kriging field) and (e)-(h) the original $T_{2 \mathrm{~m}}$ estimates from the four reanalysis datasets. The $95 \%$ significance level of the trends is indicated as in Fig. 4.

Simmonds 2012; Bromwich et al. 2013). One application of our reconstructions is therefore to serve as a benchmark of reanalysis temperature trends over all Antarctica.

Figure 7 compares the trends in the annual mean temperature from reconstructions and reanalyses during 1979-2009. The trend patterns from our four reconstructions bear very strong resemblance to each other, the small differences being mostly confined to the peninsula. The four reanalyses, on the other hand, reveal trend patterns that are drastically different not only from those of the reconstructions, but also from each other. In particular, large values occur locally, often seen as a sign of spurious changes in the time series. To help understand the origin of these differences, the temperature anomalies for several locations characterized by large trend values are plotted in Fig. 8. Four conclusions can be drawn from Figs. 7 and 8:

1) The widespread warming seen in CFSR is mainly explained by a shift in the temperature in the late 1990s (cf. the "All Antarctica" plot in Fig. 8). This shift is likely related to the beginning of the assimilation of satellite radiances from the Advanced Television and
Infrared Observation Satellite (TIROS) Operational Vertical Sounder (ATOVS) suite of instruments in late 1998, already known to have had a global impact on CFSR precipitation (Zhang et al. 2012). In comparison, none of the other reanalyses seems to have a single dominant issue similar to the ATOVS problem in CFSR.

2) ERAI exhibits considerably larger fluctuations in its temperature than the two other reanalyses or our reconstruction. The fact that these fluctuations are seen both in the analysis (ERAI-a) and the forecast (ERAI-f) fields suggests that artifacts due to the assimilation of near-surface temperature observations are likely not the main cause of the problem. One notable exception is South Pole, where only ERAI-a diverges from the other curves in the mid-1980s. Closer inspection reveals that near-surface temperature observations from this location, although available (since 1957), were surprisingly not used in ERAI prior to 1985.

3) In some cases (other than South Pole), differences between the reanalysis time series can be the result of changes in a station's location/elevation (which may 


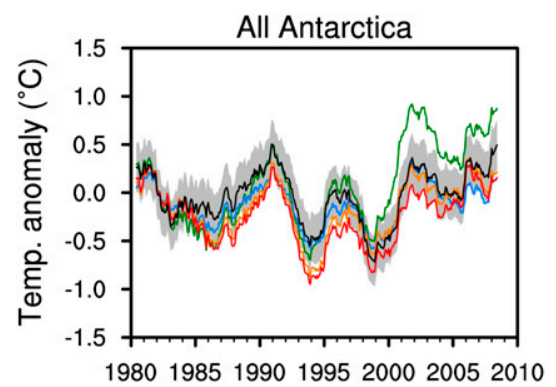

3. Eastern Ross I.S.

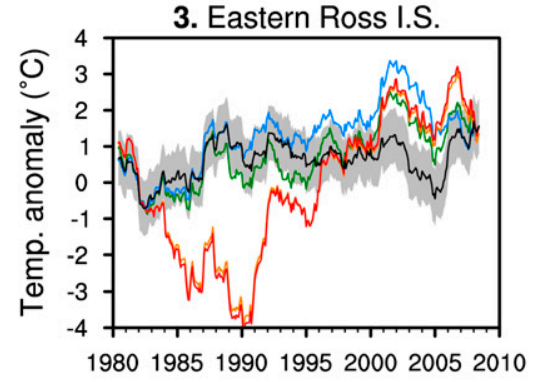

6. Amery I.S.

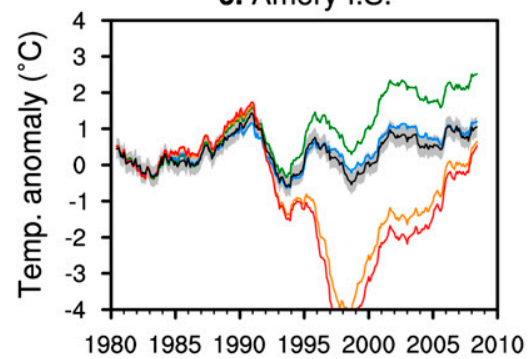

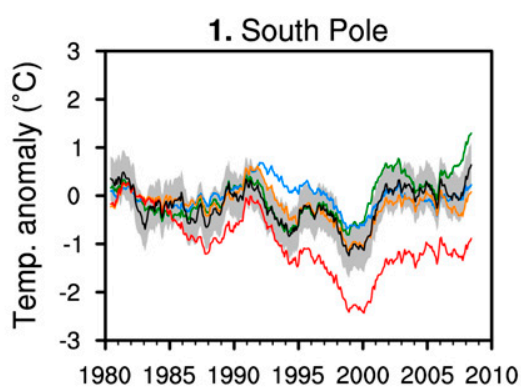

4. Filchner I.S.

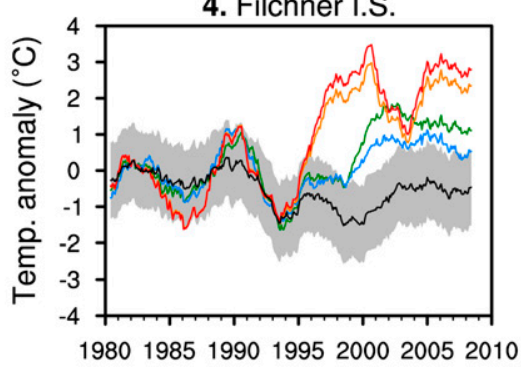

7. Casey Station vicinity

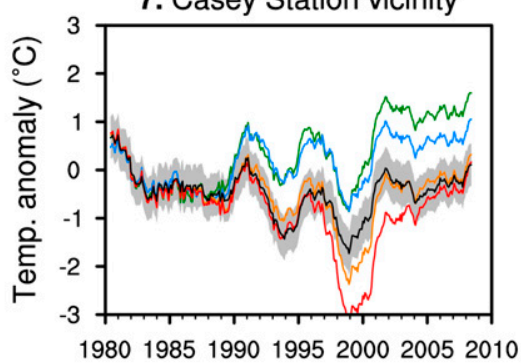

2. Western Ross I.S.

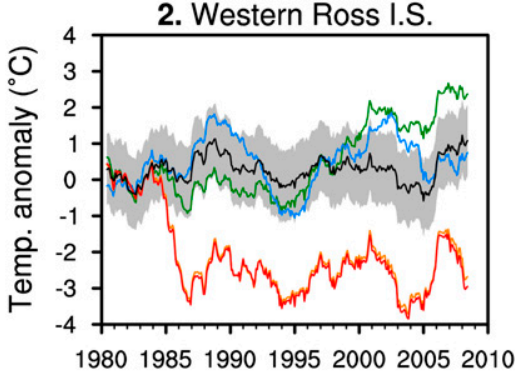

5. Dronning Maud Land
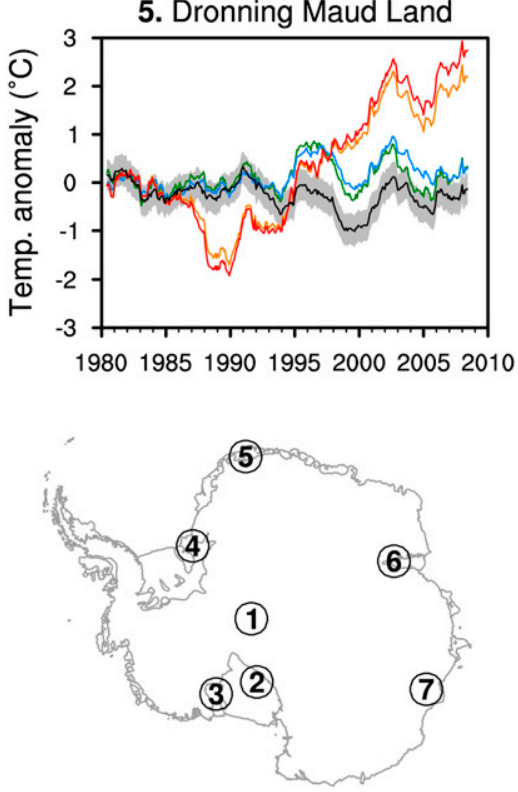

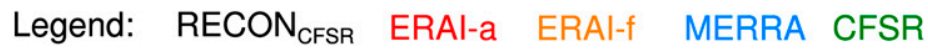

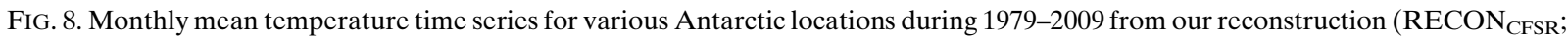
black line) and from the original $T_{2 \mathrm{~m}}$ data from the four reanalyses used this study (colored lines). The time series are shown as anomalies with respect to the first five years (1979-1984) and are smoothed with a 36-month moving average. (top left) The first plot shows the temperature anomalies spatially averaged over all Antarctica. The other plots show the temperature anomalies for the seven locations displayed on the map in the bottom-right corner. The gray shading represents the $95 \%$ confidence interval of our reconstruction $( \pm 2 \sigma)$, with $\sigma^{2}$ being the unresolved variance (estimated separately for each location).

or may not be taken into account by the reanalyses). For example, in the vicinity of Casey (location 7 in Fig. 8), the reanalyses start diverging in the late 1980 s, that is, around the time of the opening of a new station located $28 \mathrm{~m}$ higher above sea level than the previous facility (cf. Australian Bureau of Meteorology, www.bom.gov.au/climate/data/). Similarly, in coastal Dronning Maud Land (location 5 in Fig. 8), the relocation of the South African station, South African National Antarctic Expedition (SANAE), from a coastal ice shelf to the top of a nunatak in the late 1990s may explain the marked differences between the reanalyses. Further investigation would certainly help confirm these hypotheses.
4) One advantage of our reconstructions is their temporal consistency since, unlike the reanalyses, they rely on a fixed network of observations. Although greater consistency (clearly apparent in Fig. 8) can be considered "more realistic," it comes with a caveat: it is not by itself proof that decadal temperature changes are correctly captured by the reconstructions.

\section{b. Influence of the SAM on Antarctic temperature change}

The tendency for the SAM to stay in its high polarity mode in austral summer and fall during recent decades is considered the main atmospheric mechanism responsible 


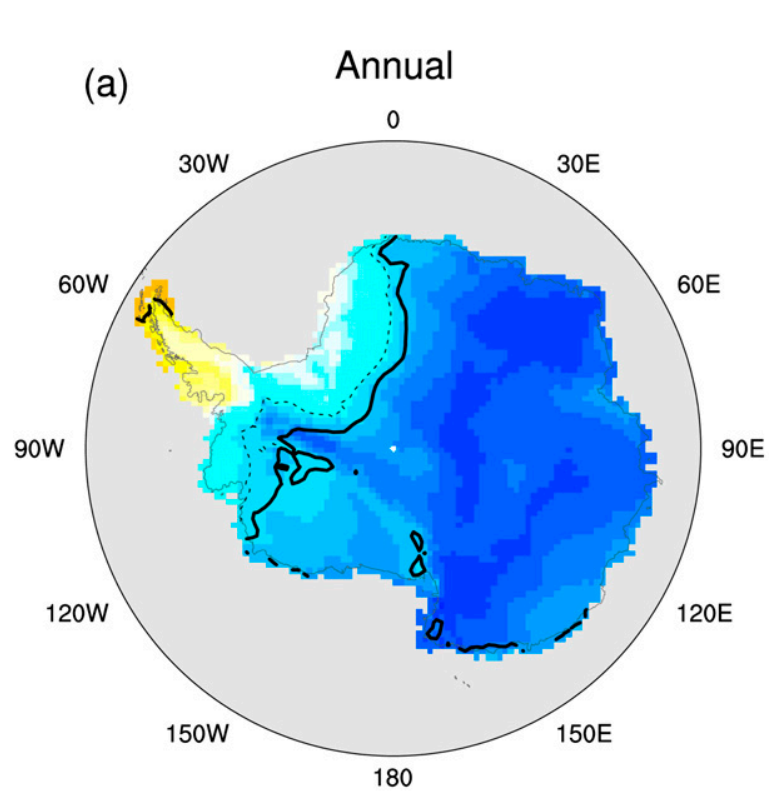

(b)
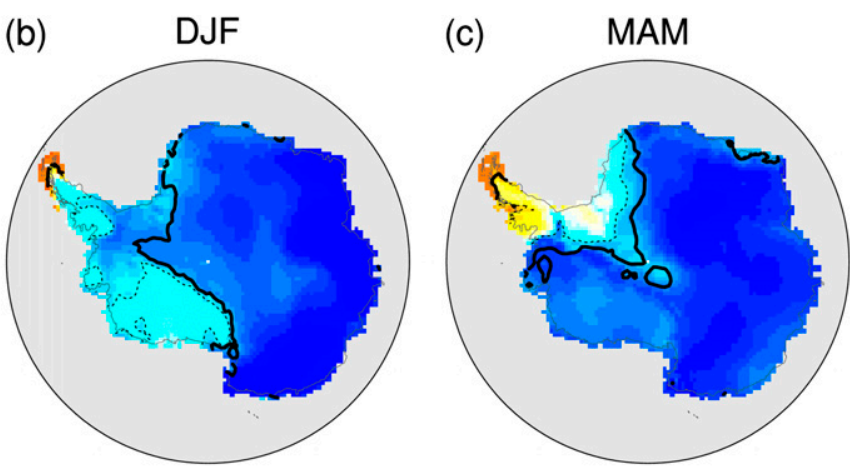

(d)
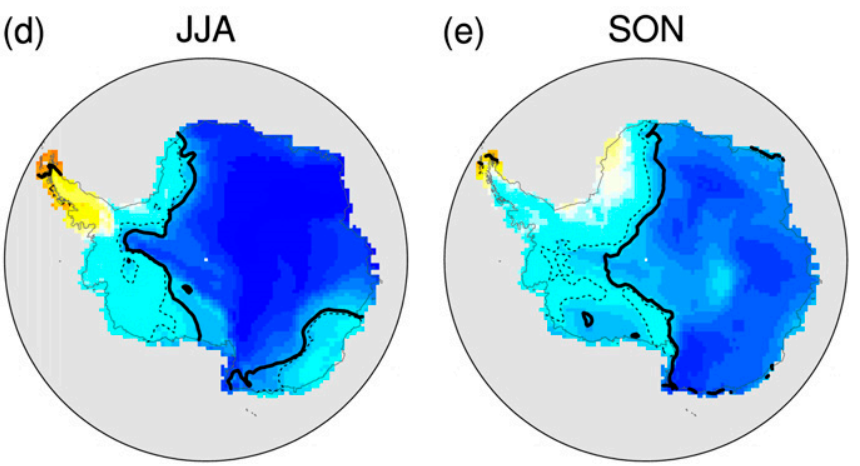

FIG. 9. Pearson's coefficient of correlation between the annual (or seasonal) mean temperatures from RECON CFSR $_{\text {at every grid point }}$ in Antarctica and the annual (or seasonal) SAM index from Marshall (2003). The correlations are calculated for the 1958-2012 period (1959-2012 for DJF) and are based on linearly detrended time series. The 95\% significance level of the correlation is indicated as in Fig. 4.

for modest temperature changes or cooling in East Antarctica (Thompson and Solomon 2002; Turner et al. 2005; Marshall 2007; Thompson et al. 2011). Note that the actual contribution of the SAM to the concurrent rapid warming of the peninsula, particularly in the fall, is debated (Ding and Steig 2013). In this section, we use our reconstruction (RECON $\left.\mathrm{RFSR}_{\mathrm{C}}\right)$ to reexamine the SAMtemperature relationships in Antarctica by expanding, both spatially (particularly over West Antarctica) or temporally, upon previous studies (e.g., Kwok and Comiso 2002; Thompson and Solomon 2002; Schneider et al. 2004, 2012a,b; Van den Broeke and van Lipzig 2004; Marshall et al. 2006, 2013; Marshall 2007; Fogt et al. 2012). These relationships are described by the correlation maps shown in Fig. 9. The correlations are calculated only for 19582012. As such, they do not capture the interdecadal variability of the relationships seen in certain areas (see, e.g., Marshall et al. 2011, 2013), and should therefore only be regarded as the dominant characteristics during this 55-yr period. Note that the correlation patterns are very consistent across our four reconstructions (cf. Fig. S8 in the supplemental material).

A high-polarity SAM (positive SAM index) is typically associated with lower temperatures in East Antarctica. This cooling effect stems both from reduced meridional heat exchange within the troposphere, and from reduced downward turbulent heat flux near the ice sheet's surface (Van den Broeke and van Lipzig 2004). The correlations are most negative in DJF within 500$1000 \mathrm{~km}$ from the coast (the katabatic zone) and are generally lower, yet still statistically significant, in SON. The western edge of East Antarctica $\left(0^{\circ}-40^{\circ} \mathrm{W}\right)$ stands out with insignificant correlations in all seasons but DJF. This feature is consistent with the reversal of the sign of the SAM-temperature relationship at Halley Station (Marshall et al. 2011).

In the Antarctic Peninsula, the stronger circumpolar flow associated with a positive SAM index enhances warm air advection across the region, which in turn favors positive temperature anomalies, especially on the eastern side (Marshall et al. 2006; van Lipzig et al. 2008). However, Fig. 9 indicates that significant positive correlations are restricted to the very northern tip of the peninsula, and temperatures in the rest of the region are positively correlated with the SAM only during MAM and JJA, yet without statistical significance. This overall lack of statistical significance can be explained by the prominent influence of the tropics, especially El NiñoSouthern Oscillation (ENSO), on atmospheric variability in and around the peninsula (Kwok and Comiso 
TABLE 6. Trends in the annual and seasonal SAM index from Marshall (2003) and SAM-congruent temperature trends $\left({ }^{\circ} \mathrm{C}\right.$ decade ${ }^{-1}$ ) per Antarctic region during 1958-2012 (1959-2012 for DJF). "All”" stands for all Antarctica. SAM index trends are in units of standard deviation per decade (the standard deviation is calculated for 1958-2012). The error bounds of the trends represent the $95 \%$ confidence interval $\left( \pm 2 \sigma_{b}\right.$ for SAM index trends, $\pm 2 \sigma_{b^{\prime}}$ for SAM-congruent trends). Boldface denotes trends statistically significant at this confidence level.

\begin{tabular}{|c|c|c|c|c|c|}
\hline & \multirow[b]{2}{*}{ Trends in SAM index } & \multicolumn{4}{|c|}{ SAM-congruent temperature trends } \\
\hline & & All & East & West & Peninsula \\
\hline Annual & $\mathbf{0 . 2 7} \pm \mathbf{0 . 1 6}$ & $-0.08 \pm 0.06$ & $-\mathbf{0 . 0 9} \pm \mathbf{0 . 0 7}$ & $-\mathbf{0 . 0 7} \pm \mathbf{0 . 0 7}$ & $0.03 \pm 0.09$ \\
\hline DJF & $\mathbf{0 . 2 3} \pm \mathbf{0 . 1 8}$ & $-\mathbf{0 . 1 0} \pm \mathbf{0 . 0 9}$ & $-\mathbf{0 . 1 1} \pm \mathbf{0 . 1 0}$ & $-0.07 \pm 0.08$ & $-0.01 \pm 0.05$ \\
\hline MAM & $0.24 \pm 0.19$ & $-0.16 \pm 0.13$ & $-0.18 \pm 0.15$ & $-0.15 \pm 0.14$ & $0.06 \pm 0.10$ \\
\hline JJA & $0.12 \pm 0.19$ & $-0.08 \pm 0.13$ & $-0.10 \pm 0.16$ & $-0.06 \pm 0.10$ & $0.05 \pm 0.10$ \\
\hline SON & $-0.01 \pm 0.20$ & $0.00 \pm 0.08$ & $0.00 \pm 0.08$ & $0.00 \pm 0.07$ & $0.00 \pm 0.01$ \\
\hline
\end{tabular}

2002; Schneider et al. 2012a; Ding and Steig 2013; Clem and Fogt 2013). As mentioned above for the temperature trends, one should keep in mind the more uncertain quality of our reconstruction in the peninsula (especially in DJF and MAM) when interpreting the correlation patterns.

In West Antarctica, the SAM-temperature correlations are negative everywhere throughout the year but-except in MAM-are small overall and not statistically significant. The contrast with respect to East Antarctica can be traced, again, to a greater imprint of ENSO in West Antarctica (e.g., Bromwich et al. 2000, 2004; Guo et al. 2004; Gregory and Noone 2008; Schneider and Steig 2008; Okumura et al. 2012). On the annual scale, the area of significant negative correlations is roughly limited to the Ross Sea sector of West Antarctica. This highlights the contrasting climate variability between the eastern and western sides of West Antarctica that is known from previous studies (e.g., Genthon et al. 2003; Kaspari et al. 2004).

The overall contribution of SAM changes to Antarctic temperature trends is estimated by calculating SAMcongruent trends (Table 6). This contribution is only apparent in the two seasons (DJF and MAM) during which the SAM index exhibits statistically significant (positive) trends since 1958. These trends have had a statistically significant cooling effect in East Antarctica (in DJF and MAM) and West Antarctica (in MAM only). By testing the sensitivity of the SAM-congruent trends to the time period (Fig. 10), we find that the SAM-related cooling is most robust in East Antarctica in DJF, that it is consistently weak and insignificant in West Antarctica in the same season, and that it is often marginally significant both in East and West Antarctica in MAM. Given that the temperature trends in DJF and MAM are already positive or near zero (Table 5), it is clear that the changes in the SAM in recent decades have mitigated what could have been a stronger and more significant Antarctic warming, as other studies have suggested (Marshall 2007; Gillett et al. 2008; Screen and Simmonds 2012).

\section{Summary and conclusions}

The temperature reconstruction presented in this paper comes after several studies aiming to extend our knowledge of temperature change over all Antarctica back to the 1957-58 IGY by exploiting the information from sparse long-term instrumental records (Chapman and Walsh 2007; S09; M10; O11). Our own contribution to this effort is primarily motivated by the recent release of a new temperature record for Byrd, which happens to be especially important for reconstructing past temperatures in West Antarctica. As in M10, our spatial interpolation method uses a kriging framework aided by spatiotemporal temperature covariances derived from global reanalyses. The reanalysis data used here are taken from four different $T_{2 \mathrm{~m}}$ datasets: MERRA, CFSR, ERAI analysis, and ERAI forecast. Four reconstructions are generated as a result. Our evaluation finds higher skill in the CFSR-based reconstruction $\left(\mathrm{RECON}_{\mathrm{CFSR}}\right)$, which is the one whose results are primarily shown and discussed throughout the paper. Our main findings can be summarized as follows:

1) The reconstructed temperature time series spatially averaged over the three Antarctic regions show statistically significant warming throughout the year in the Antarctic Peninsula, in SON and JJA in West Antarctica, and in SON in East Antarctica during the 1958-2012 period. While the West Antarctic warming in SON is quite robust to the calculation period, it is less so for the two other trends.

2) The annual warming is of similar magnitude both in central West Antarctica and in most of the peninsula, rather than concentrated either in the former (as in S09) or in the latter (as in O11). However, the seasonality and spatial patterns of the trends suggest different origins to the warming in these two regions.

3) A sharp contrast appears in the temperature trend maps on either sides of the Transantarctic Mountains, particularly in JJA and SON. The same contrast is also seen in the results from S09 but is less 

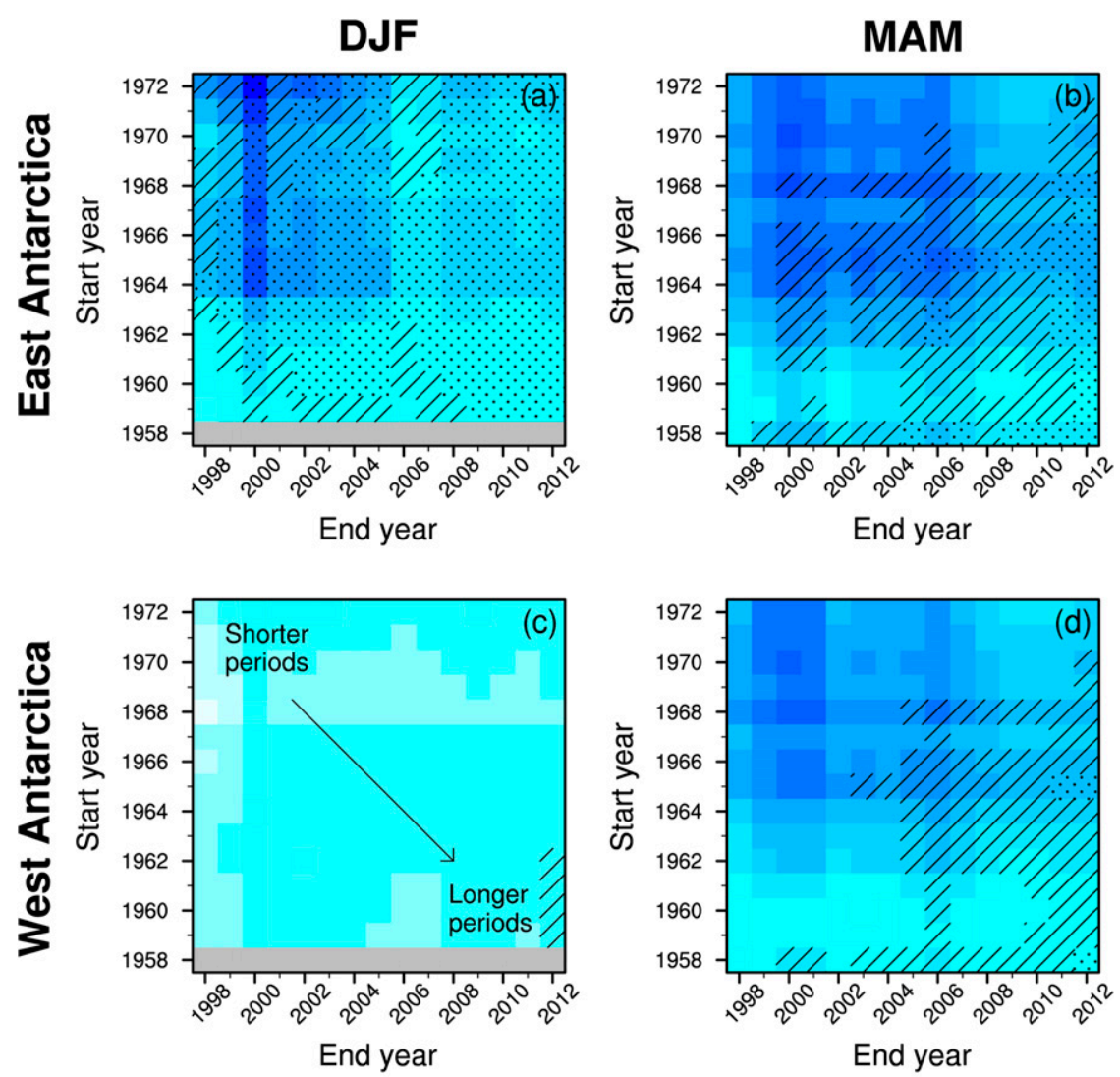

Temperature trends $\left({ }^{\circ} \mathrm{C}\right.$ decade $\left.{ }^{-1}\right)$

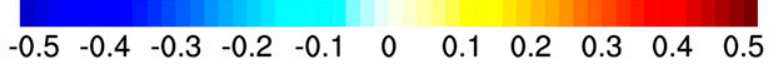

FIG. 10. SAM-congruent temperature trends calculated for various time periods starting within the first $15 \mathrm{yr}$ ( $y$ axis) and ending within the last $15 \mathrm{yr}$ ( $x$ axis) of our reconstruction $\left(\right.$ RECON $\left._{\text {CFSR }}\right)$. The trends are shown for (top) East Antarctica and (bottom) West Antarctica and only for the two seasons (DJF and MAM) during which the trend in the SAM index is statistically significant (cf. Table 6). DJF trends are only from 1959 onward. Hatching and stippling indicate trends statistically significant at the $90 \%$ and $95 \%$ levels (respectively). In both cases, the trend uncertainty accounts both for the error of the SAM-temperature regression coefficient and for the temperature reconstruction error.

prominent in the other reconstructions. This dividing line is consistent with warming primarily caused by maritime air being advected from the north and constrained by the topographic barrier once it penetrates onto West Antarctica.

4) The area of strong warming in SON encompasses virtually all West Antarctica except for the Ronne Ice Shelf. The tongue-shaped pattern apparent in the trend map provides further indication of the advective nature of the warming and is consistent with the decreasing atmospheric pressure-geopotential height observed in the adjacent sector of the Southern Ocean (Schneider et al. 2012a; Bromwich et al. 2013).

5) In JJA, our reconstruction suggests warming on both sides of West Antarctica as in S09. As such, it does not confirm the cooling of the western sector (facing the Ross Sea) found by M10 and O11. Our finding of warming of the western sector is consistent with tropically forced changes in the atmospheric circulation (more anticyclonic) over the Amundsen Sea reported by Ding et al. (2011) for the post-1979 period. The same pattern of atmospheric changes can less readily account for the longerterm warming of the eastern sector (the only area in West Antarctica with statistically significant trends during 1958-2012).

We further employ our temperature reconstruction(s) to investigate two additional issues. The first issue deals with the reliability of the temperature trends in the four 
reanalysis datasets used to derive the temperature covariances. Our analysis highlights spurious temperature changes in various parts of Antarctica in each reanalysis, with varying characteristics. For example, the impact of the assimilation of ATOVS data is clearly seen in CFSR in the late 1990s. Large temperature shifts in ERAI cast doubt on its reliability but do not seem tied to a single problem. These artifacts in the time series represent one important source of error in our reconstruction, although their impact can be reduced by linearly detrending the reanalysis data. Beyond the scope of our reconstruction, and given the prominent role of global reanalyses in shaping our understanding of Antarctic climate change in recent decades, it would be desirable to understand the origin of these problems in order to avoid their reappearance in future reanalyses.

The second issue is the characterization of the influence of the SAM on Antarctic temperatures during the 1958-2012 period. Our analysis largely confirms the spatial pattern of the SAM-temperature relationship described in previous studies but provides additional insight on this relationship in West Antarctica. We show, via the calculation of SAM-congruent temperature trends, that the positive trend in the SAM index in recent decades has had a statistically significant cooling effect in East Antarctica in DJF and MAM and in West Antarctica in MAM. This SAM-related cooling may be interpreted as the additional warming that might occur if the SAM were to revert to its average pre-1980 ("preozone hole") state. Future weakening of the SAM may result, for example, from the Antarctic ozone recovery projected for the rest of the twenty-first century, but many sources of uncertainty remain regarding this scenario, pertaining to current climate model projections (Perlwitz et al. 2008; Zheng et al. 2013), to the role of natural variability in SAM changes (Marshall et al. 2004), or to interactions between SAM and ENSO (Fogt et al. 2011). The uncertain nature of the relationship between SAM and Antarctic temperatures (Bitz and Polvani 2012; Marshall et al. 2013) is another item to add to the list. Until reanalysis data in Antarctica can extend reliably back to the IGY (or beyond), temperature reconstructions will likely remain an important tool to investigate this issue.

Acknowledgments. This research was supported by NASA Grant NN12AI29G and by National Science Foundation Grants PLR-1049089 and PLR-1341695. We thank Andrew Monaghan for his temperature reconstruction data and for his insight at various stages of this work. We are also grateful to three anonymous reviewers for their comments, which helped improve the paper.

\section{APPENDIX A}

\section{Optimal Kriging Weights}

This appendix details the content of Eq. (2) used to determine the weights of the observations in the spatial interpolation. Using the same notation as in section $2 b$, we define the following variables and parameters of the equation (with $i=1, \ldots, N$ and $j=1, \ldots, N$ ):

- $N$, the number of observations;

- $\mathbf{x}_{i}$, the location (nearest grid point) of the $i$ th observation;

- $\mathbf{x}$, the location (grid point) where the temperature anomaly must be estimated;

- $r_{i}^{2}\left(\mathbf{x}_{j}\right)$, the squared Pearson's correlation between the model temperature at the grid point closest to the $i$ th observation and the model temperature at the grid point closest to the $j$ th observation [note that $\left.r_{i}^{2}\left(\mathbf{x}_{j}\right)=r_{j}^{2}\left(\mathbf{x}_{i}\right)\right]$

- $r_{i}^{2}(\mathbf{x})$, the squared Pearson's correlation between the model temperature at the grid point closest to the $i$ th observation and the model temperature at a certain location (grid point) $\mathbf{x}$;

- $\alpha$, a parameter known as the Lagrange multiplier; and

- $\lambda_{i}$, the weight assigned to the $i$ th observation (i.e., the unknown).

The theory of ordinary kriging (e.g., Cressie 1993; Olea 1999) dictates that the weighting coefficients $\lambda_{i}$ are optimal if they minimize the estimation error (kriging variance). This condition requires the coefficients to be solutions of the following system of $N+1$ linear equations:

$$
\left\{\begin{array}{c}
\sum_{i=1}^{N} \lambda_{i} r_{1}^{2}\left(\mathbf{x}_{i}\right)+\alpha=r_{1}^{2}(\mathbf{x}) \\
\sum_{i=1}^{N} \lambda_{i} r_{2}^{2}\left(\mathbf{x}_{i}\right)+\alpha=r_{2}^{2}(\mathbf{x}) \\
\cdots \\
\cdots \\
\sum_{i=1}^{N} \lambda_{i} r_{N}^{2}\left(\mathbf{x}_{i}\right)+\alpha=r_{N}^{2}(\mathbf{x}) \\
\sum_{i=1}^{N} \lambda_{i}=1
\end{array}\right.
$$

In matrix notation, the system becomes

$$
\underbrace{\left[\begin{array}{cccc}
r_{1}^{2}\left(\mathbf{x}_{1}\right) & \ldots & r_{1}^{2}\left(\mathbf{x}_{N}\right) & 1 \\
\vdots & \ddots & \vdots & 1 \\
r_{N}^{2}\left(\mathbf{x}_{1}\right) & \ldots & r_{N}^{2}\left(\mathbf{x}_{N}\right) & 1 \\
1 & 1 & 1 & 0
\end{array}\right]}_{\mathbf{A}^{*}} \underbrace{\left[\begin{array}{c}
\lambda_{1} \\
\vdots \\
\lambda_{N} \\
\alpha
\end{array}\right]}_{\boldsymbol{\lambda}^{*}}=\underbrace{\left[\begin{array}{c}
r_{1}^{2}(\mathbf{x}) \\
\vdots \\
r_{N}^{2}(\mathbf{x}) \\
1
\end{array}\right]}_{\mathbf{b}^{*}}
$$




\section{APPENDIX B}

\section{Definition of Statistical Parameters}

Our evaluation statistics include the average explained variance $\left(R^{2}\right.$, the coefficient of determination) during the "full reconstruction period" (i.e., the longest period of overlap between reconstruction and observationsreanalyses), and the coefficient of efficiency (CE) during the calibration period. The two statistics are defined as in Cook et al. (1994, 1999), the only difference being that these authors restrict the calculation of $R^{2}$ to their calibration period whereas the full reconstruction period is used here (as in O11).

The $R^{2}$ coefficient is calculated as follows:

$$
R^{2}=1.0-\frac{\sum\left(y_{t}-\hat{y}_{t}\right)^{2}}{\sum\left(y_{t}-\bar{y}_{\mathrm{FR}}\right)^{2}},
$$

where $y_{t}$ are the temperature anomalies from the validation data (observations or reanalysis), $\hat{y}_{t}$ are the temperature anomalies from our reconstruction, and $t$ is a point in time (month, season, or year) during the full reconstruction period; $\bar{y}_{\mathrm{FR}}$ is the mean of $y_{t}$ during the same period. The CE statistic is calculated in a very similar fashion:

$$
\mathrm{CE}=1.0-\frac{\sum\left(y_{t}-\hat{y}_{t}\right)^{2}}{\sum\left(y_{t}-\bar{y}_{v}\right)^{2}} .
$$

In this case, $y_{t}, \hat{y}_{t}$, and $\bar{y}_{v}$ are all restricted to the verification period. The reference period for all anomalies is the full reconstruction period. It follows that, in our particular case, $\bar{y}_{\mathrm{FR}}=0$ and (in general) $\bar{y}_{v} \neq 0$.

The $R^{2}$ and CE statistics compare the error of the reconstruction to the error arising from simply using the climatological mean. They range from $-\infty$ to +1 , with positive values indicating greater skill than climatology (our goal here). Note that $R^{2}$ differs from the squared Pearson's correlation coefficient, $r^{2}$. Both would be equivalent if $\hat{y}$ were based on a simple univariate least squares linear regression of $y$ (Ott 1993), which is not the case here. Unlike $r^{2}, R^{2}$ can take on negative values (cf. Fig. S2 in the supplemental material). In those instances, the problem may reside in the reanalysis data rather than the reconstruction. Further details about the $R^{2}$ and CE statistics can be found in Cook et al. $(1994,1999)$.

\section{REFERENCES}

Abram, N. J., and Coauthors, 2013: Acceleration of snow melt in an Antarctic Peninsula ice core during the twentieth century. Nat. Geosci., 6, 404-411, doi:10.1038/ngeo1787.
Barrett, B. E., K. W. Nicholls, T. Murray, A. M. Smith, and D. G. Vaughan, 2009: Rapid recent warming on Rutford Ice Stream, West Antarctica, from borehole thermometry. Geophys. Res. Lett., 36, L02708, doi:10.1029/2008GL036369.

Bengtsson, L., S. Koumoutsaris, and K. Hodges, 2011: Large-scale surface mass balance of ice sheets from a comprehensive atmospheric model. Surv. Geophys., 32, 459-474, doi:10.1007/ s10712-011-9120-8.

Bindschadler, R., 2006: The environment and evolution of the West Antarctic ice sheet: Setting the stage. Philos. Trans. Roy. Soc., 364A, 1583-1605, doi:10.1098/rsta.2006.1790.

— ronmental forcing and their use in projecting future sea level (the SeaRISE project). J. Glaciol., 59, 195-224, doi:10.3189/ 2013JoG12J125.

Bitz, C. M., and L. M. Polvani, 2012: Antarctic climate response to stratospheric ozone depletion in a fine resolution ocean climate model. Geophys. Res. Lett., 39, L20705, doi:10.1029/ 2012GL053393.

Bracegirdle, T. J., 2013: Climatology and recent increase of westerly winds over the Amundsen Sea derived from six reanalyses. Int. J. Climatol., 33, 843-851, doi:10.1002/joc.3473.

_ spheric pressure and temperature in the latest global reanalyses. J. Climate, 25, 7138-7146, doi:10.1175/JCLI-D-11-00685.1.

Bromwich, D. H., and R. L. Fogt, 2004: Strong trends in the skill of the ERA-40 and NCEP-NCAR reanalyses in the high and middle latitudes of the Southern Hemisphere, 1958-2001. J. Climate, 17, 4603-4619, doi:10.1175/3241.1.

, A. N. Rogers, P. Kållberg, R. I. Cullather, J. W. C. White, and K. J. Kreutz, 2000: ECMWF analyses and reanalyses depiction of ENSO signal in Antarctic precipitation. J. Climate, 13, 1406-1420, doi:10.1175/1520-0442(2000)013<1406: EAARDO $>2.0 . \mathrm{CO} ; 2$.

— A. J. Monaghan, and Z. Guo, 2004: Modeling the ENSO modulation of Antarctic climate in the late 1990s with Polar MM5. J. Climate, 17, 109-132, doi:10.1175/1520-0442(2004)017<0109: MTEMOA $>2.0 . \mathrm{CO} ; 2$.

—, R. L. Fogt, K. I. Hodges, and J. E. Walsh, 2007: A tropospheric assessment of the ERA-40, NCEP, and JRA-25 global reanalyses in the polar regions. J. Geophys. Res., 112, D10111, doi:10.1029/2006JD007859.

_ changes in Antarctic and Southern Ocean precipitation since 1989 in contemporary global reanalyses. J. Climate, 24, 41894209, doi:10.1175/2011JCLI4074.1.

,,,--- M. A. Lazzara, L. M. Keller, G. A. Weidner, and A. B. Wilson, 2013: Central West Antarctica among the most rapidly warming regions on Earth. Nat. Geosci., 6, 139-145, doi:10.1038/ngeo1671.

$-,-,-,-\longrightarrow,-,-, \ldots, 2014$ : Corrigendum: Central West Antarctica among the most rapidly warming regions on Earth. Nat. Geosci., 7, 76, doi:10.1038/ngeo2016.

Chapman, W. L., and J. E. Walsh, 2007: A synthesis of Antarctic temperatures. J. Climate, 20, 4096-4117, doi:10.1175/JCLI4236.1.

Church, J., and Coauthors, 2013: Sea level change. Climate Change 2013: The Physical Science Basis. T. Stocker et al., Eds., Cambridge University Press, 1137-1216.

Clem, K. R., and R. L. Fogt, 2013: Varying roles of ENSO and SAM on the Antarctic Peninsula climate in austral spring. J. Geophys. Res. Atmos., 118, 11481-11492, doi:10.1002/jgrd.50860.

Comiso, J. C., 2000: Variability and trends in Antarctic surface temperatures from in situ and satellite infrared measurements. 
J. Climate, 13, 1674-1696, doi:10.1175/1520-0442(2000)013<1674: VATIAS $>2.0 . \mathrm{CO} ; 2$.

Cook, E. R., K. R. Briffa, and P. D. Jones, 1994: Spatial regression methods in dendroclimatology: A review and comparison of two techniques. Int. J. Climatol., 14, 379-402, doi:10.1002/ joc.3370140404.

— D. M. Meko, D. W. Stahle, and M. K. Cleaveland, 1999: Drought reconstructions for the continental United States. J. Climate, 12, 1145-1162, doi:10.1175/1520-0442(1999)012<1145: DRFTCU $>2.0 . \mathrm{CO} ; 2$.

Cressie, N. A., 1993: Statistics for Spatial Data. Wiley, 900 pp.

Cullather, R. I., and M. G. Bosilovich, 2011: The moisture budget of the polar atmosphere in MERRA. J. Climate, 24, 28612879, doi:10.1175/2010JCLI4090.1.

Dee, D. P., and Coauthors, 2011: The ERA-Interim reanalysis: Configuration and performance of the data assimilation system. Quart. J. Roy. Meteor. Soc., 137, 553-597, doi:10.1002/ qj.828.

Depoorter, M. A., J. L. Bamber, J. A. Griggs, J. T. M. Lenaerts, S. R. M. Ligtenberg, M. R. van den Broeke, and G. Moholdt, 2013: Calving fluxes and basal melt rates of Antarctic ice shelves. Nature, 502, 89-92, doi:10.1038/nature12567.

Ding, Q., and E. J. Steig, 2013: Temperature change on the Antarctic Peninsula linked to the tropical Pacific. J. Climate, 26, 7570-7585, doi:10.1175/JCLI-D-12-00729.1.

—,,- D. S. Battisti, and M. Küttel, 2011: Winter warming in West Antarctica caused by central tropical Pacific warming. Nat. Geosci., 4, 398-403, doi:10.1038/ngeo1129.

,,--- , and J. M. Wallace, 2012: Influence of the tropics on the southern annular mode. J. Climate, 25, 6330-6348, doi:10.1175/JCLI-D-11-00523.1.

Fogt, R. L., D. H. Bromwich, and K. M. Hines, 2011: Understanding the SAM influence on the South Pacific ENSO teleconnection. Climate Dyn., 36, 1555-1576, doi:10.1007/ s00382-010-0905-0.

_ _ J. M. Jones, and J. Renwick, 2012: Seasonal zonal asymmetries in the southern annular mode and their impact on regional temperature anomalies. J. Climate, 25, 6253-6270, doi:10.1175/JCLI-D-11-00474.1.

Fréville, H., E. Brun, G. Picard, N. Tatarinova, L. Arnaud, C. Lanconelli, C. Reijmer, and M. van den Broeke, 2014 Using MODIS land surface temperatures and the Crocus snow model to understand the warm bias of ERA-Interim reanalyses at the surface in Antarctica. Cryosphere Discuss., 8, 55-84, doi:10.5194/tcd-8-55-2014.

Genthon, C., G. Krinner, and M. Sacchettini, 2003: Interannual Antarctic tropospheric circulation and precipitation variability. Climate Dyn., 21, 289-307, doi:10.1007/s00382-003-0329-1.

Gillett, N. P., D. A. Stone, P. A. Stott, T. Nozawa, A. Y. Karpechko, G. C. Hegerl, M. F. Wehner, and P. D. Jones, 2008: Attribution of polar warming to human influence. Nat. Geosci., 1, 750-754, doi:10.1038/ngeo338.

Goosse, H., and Coauthors, 2012: Antarctic temperature changes during the last millennium: Evaluation of simulations and reconstructions. Quat. Sci. Rev., 55, 75-90, doi:10.1016/ j.quascirev.2012.09.003.

Gregory, J., and P. Huybrechts, 2006: Ice-sheet contributions to future sea-level change. Philos. Trans. Roy. Soc., A364, 1709-1732.

Gregory, S., and D. Noone, 2008: Variability in the teleconnection between the El Niño-Southern Oscillation and West Antarctic climate deduced from West Antarctic ice core isotope records. J. Geophys. Res., 113, D17110, doi:10.1029/2007JD009107.
Guo, Z., D. H. Bromwich, and K. Hines, 2004: Modeled Antarctic precipitation. Part II: ENSO modulation over West Antarctica. J. Climate, 17, 448-465, doi:10.1175/1520-0442(2004)017<0448: MAPPIE $>2.0 . \mathrm{CO} ; 2$.

Hines, K. M., D. H. Bromwich, and G. J. Marshall, 2000: Artificial surface pressure trends in the NCEP-NCAR reanalysis over the Southern Ocean and Antarctica. J. Climate, 13, 3940-3952, doi:10.1175/1520-0442(2000)013<3940:ASPTIT>2.0.CO;2.

Ho, M., A. S. Kiem, and D. C. Verdon-Kidd, 2012: The southern annular mode: A comparison of indices. Hydrol. Earth Syst. Sci., 16, 967-982, doi:10.5194/hess-16-967-2012.

Jacobs, S. S., A. Jenkins, C. F. Giulivi, and P. Dutrieux, 2011: Stronger ocean circulation and increased melting under Pine Island Glacier ice shelf. Nat. Geosci., 4, 519-523, doi:10.1038/ ngeo1188.

Joughin, I., and R. B. Alley, 2011: Stability of the West Antarctic ice sheet in a warming world. Nat. Geosci., 4, 506-513, doi:10.1038/ngeo1194.

Kaspari, S., P. A. Mayewski, D. A. Dixon, V. B. Spikes, S. B. Sneed, M. J. Handley, and G. S. Hamilton, 2004: Climate variability in West Antarctica derived from annual accumulation-rate records from ITASE firn/ice cores. Ann. Glaciol., 39, 585-594, doi: $10.3189 / 172756404781814447$.

King, J. C., and J. C. Comiso, 2003: The spatial coherence of interannual temperature variations in the Antarctic Peninsula. Geophys. Res. Lett., 30, 1040, doi:10.1029/2002GL015580.

Krinner, G., O. Magand, I. Simmonds, C. Genthon, and J.-L. Dufresne, 2007: Simulated Antarctic precipitation and surface mass balance at the end of twentieth and twenty-first centuries. Climate Dyn., 28, 215-230, doi:10.1007/s00382-006-0177-x.

Kuipers Munneke, P., G. Picard, M. R. van den Broeke, J. T. M. Lenaerts, and E. van Meijgaard, 2012: Insignificant change in Antarctic snowmelt volume since 1979. Geophys. Res. Lett., 39, L01501, doi:10.1029/2011GL050207.

Küttel, M., E. J. Steig, Q. Ding, A. J. Monaghan, and D. S. Battisti, 2012: Seasonal climate information preserved in West Antarctic ice core water isotopes: Relationships to temperature, large-scale circulation, and sea ice. Climate Dyn., 39, 18411857, doi:10.1007/s00382-012-1460-7.

Kwok, R., and J. C. Comiso, 2002: Spatial patterns of variability in Antarctic surface temperature: Connections to the Southern Hemisphere annular mode and the Southern Oscillation. Geophys. Res. Lett., 29, 1705, doi:10.1029/2002GL015415.

Lam, N. S.-N., 1983: Spatial interpolation methods: A review. Amer. Cartogr., 10, 129-149, doi:10.1559/152304083783914958.

Ligtenberg, S., W. van de Berg, M. van den Broeke, J. Rae, and E. van Meijgaard, 2013: Future surface mass balance of the Antarctic Ice Sheet and its influence on sea level change, simulated by a regional atmospheric climate model. Climate Dyn., 41, 867-884, doi:10.1007/s00382-013-1749-1.

Mann, M. E., and S. Rutherford, 2002: Climate reconstruction using 'pseudoproxies.' Geophys. Res. Lett., 29, 1501, doi:10.1029/ 2001 GL014554.

$\longrightarrow,-$, E. Wahl, and C. Ammann, 2005: Testing the fidelity of methods used in proxy-based reconstructions of past climate. J. Climate, 18, 4097-4107, doi:10.1175/JCLI3564.1.

_, Z. Zhang, M. K. Hughes, R. S. Bradley, S. K. Miller, S. Rutherford, and F. Ni, 2008: Proxy-based reconstructions of hemispheric and global surface temperature variations over the past two millennia. Proc. Natl. Acad. Sci. USA, 105, 13252-13 257, doi:10.1073/pnas.0805721105.

Marshall, G. J., 2002: Trends in Antarctic geopotential height and temperature: A comparison between radiosonde and 
NCEP-NCAR reanalysis data. J. Climate, 15, 659-674, doi:10.1175/1520-0442(2002)015<0659:TIAGHA > 2.0.CO;2.

- 2003: Trends in the southern annular mode from observations and reanalyses. J. Climate, 16, 4134-4143, doi:10.1175/ 1520-0442(2003)016<4134:TITSAM > 2.0.CO;2.

_ 2007 : Half-century seasonal relationships between the southern annular mode and Antarctic temperatures. Int. J. Climatol., 27, 373-383, doi:10.1002/joc.1407.

- P. A. Stott, J. Turner, W. M. Connolley, J. C. King, and T. A. Lachlan-Cope, 2004: Causes of exceptional atmospheric circulation changes in the Southern Hemisphere. Geophys. Res. Lett., 31, L14205, doi:10.1029/2004GL019952.

— A. Arr, N. P. M. van Lipzig, and J. C. King, 2006: The impact of a changing Southern Hemisphere annular mode on Antarctic Peninsula summer temperatures. J. Climate, 19, 53885404, doi:10.1175/JCLI3844.1.

— S. Di Battista, S. Naik, and M. Thamban, 2011: Analysis of a regional change in the sign of the SAM-temperature relationship in Antarctica. Climate Dyn., 36, 277-287, doi:10.1007/ s00382-009-0682-9.

- A. Orr, and J. Turner, 2013: A predominant reversal in the relationship between the SAM and East Antarctic temperatures during the twenty-first century. J. Climate, 26, 5196-5204, doi:10.1175/JCLI-D-12-00671.1.

Monaghan, A. J., and Coauthors, 2006: Insignificant change in Antarctic snowfall since the International Geophysical Year. Science, 313, 827-831, doi:10.1126/science.1128243.

- D. H. Bromwich, W. Chapman, and J. C. Comiso, 2008: Recent variability and trends of Antarctic near-surface temperature. J. Geophys. Res., 113, D04105, doi:10.1029/2007JD009094.

Muto, A., T. A. Scambos, K. Steffen, A. G. Slater, and G. D. Clow, 2011: Recent surface temperature trends in the interior of East Antarctica from borehole firn temperature measurements and geophysical inverse methods. Geophys. Res. Lett., 38, L15502, doi:10.1029/2011GL048086.

Nicolas, J. P., and D. H. Bromwich, 2011a: Climate of West Antarctica and influence of marine air intrusions. J. Climate, 24, 49-67, doi:10.1175/2010JCLI3522.1.

- , and $-2011 \mathrm{~b}$ : Precipitation changes in high southern latitudes from global reanalyses: A cautionary tale. Surv. Geophys., 32, 475-494, doi:10.1007/s10712-011-9114-6.

O'Donnell, R., N. Lewis, S. McIntyre, and J. Condon, 2011: Improved methods for PCA-based reconstructions: Case study using the Steig et al. (2009) Antarctic temperature reconstruction. J. Climate, 24, 2099-2115, doi:10.1175/2010JCLI3656.1.

Okumura, Y. M., D. Schneider, C. Deser, and R. Wilson, 2012: Decadal-interdecadal climate variability over Antarctica and linkages to the tropics: Analysis of ice core, instrumental, and tropical proxy data. J. Climate, 25, 7421-7441, doi:10.1175/ JCLI-D-12-00050.1.

Olea, R. A., 1999: Geostatistics for Engineers and Earth Scientists. Kluwer Academic, 303 pp.

Orsi, A. J., B. D. Cornuelle, and J. P. Severinghaus, 2012: Little Ice Age cold interval in West Antarctica: Evidence from borehole temperature at the West Antarctic Ice Sheet (WAIS) Divide. Geophys. Res. Lett., 39, L09710, doi:10.1029/ 2012GL051260.

Ott, R. L., 1993: An Introduction to Statistical Methods and Data Analysis. 4th ed. Duxbury, $1051 \mathrm{pp}$.

Perlwitz, J., S. Pawson, R. L. Fogt, J. E. Nielsen, and W. D. Neff, 2008: Impact of stratospheric ozone hole recovery on Antarctic climate. Geophys. Res. Lett., 35, L08714, doi:10.1029/ 2008 GL033317.
Pritchard, H. D., and D. G. Vaughan, 2007: Widespread acceleration of tidewater glaciers on the Antarctic Peninsula. J. Geophys. Res., 112, F03S29, doi:10.1029/2006JF000597.

_, S. R. M. Ligtenberg, H. A. Fricker, D. G. Vaughan, M. R. van den Broeke, and L. Padman, 2012: Antarctic ice-sheet loss driven by basal melting of ice shelves. Nature, 484, 502-505, doi:10.1038/nature10968.

Reusch, D. B., and R. B. Alley, 2004: A 15-year West Antarctic climatology from six automatic weather station temperature and pressure records. J. Geophys. Res., 109, D04103, doi:10.1029/ 2003JD004178.

Richard, Y., and Coauthors, 2013: Temperature changes in the mid and high latitudes of the Southern Hemisphere. Int. J. Climatol., 33, 1948-1963, doi:10.1002/joc.3563.

Rienecker, M. M., and Coauthors, 2011: MERRA: NASA's Modern-Era Retrospective Analysis for Research and Applications. J. Climate, 24, 3624-3648, doi:10.1175/ JCLI-D-11-00015.1.

Rignot, E., G. Casassa, P. Gogineni, W. Krabill, A. Rivera, and R. Thomas, 2004: Accelerated ice discharge from the Antarctic Peninsula following the collapse of Larsen B ice shelf. Geophys. Res. Lett., 31, L18401, doi:10.1029/ 2004GL020697.

Roberts, J. L., A. D. Moy, T. D. van Ommen, M. A. J. Curran, A. P. Worby, I. D. Goodwin, and M. Inoue, 2013: Borehole temperatures reveal a changed energy budget at Mill Island, East Antarctica, over recent decades. Cryosphere, 7, 263-273, doi:10.5194/tc-7-263-2013.

Saha, S., and Coauthors, 2010: The NCEP Climate Forecast System Reanalysis. Bull. Amer. Meteor. Soc., 91, 1015-1057, doi:10.1175/ 2010BAMS3001.1.

Santer, B. D., T. M. L. Wigley, J. S. Boyle, D. J. Gaffen, J. J. Hnilo, D. Nychka, D. E. Parker, and K. E. Taylor, 2000: Statistical significance of trends and trend differences in layer-average atmospheric temperature time series. J. Geophys. Res., 105, 7337-7356, doi:10.1029/1999JD901105.

Scambos, T. A., J. A. Bohlander, C. A. Shuman, and P. Skvarca, 2004: Glacier acceleration and thinning after ice shelf collapse in the Larsen B embayment, Antarctica. Geophys. Res. Lett., 31, L18402, doi:10.1029/2004GL020670.

Schneider, D. P., and E. J. Steig, 2008: Ice cores record significant 1940s Antarctic warmth related to tropical climate variability. Proc. Natl. Acad. Sci. USA, 105, 12154-12158, doi:10.1073/ pnas.0803627105.

,-- , and J. C. Comiso, 2004: Recent climate variability in Antarctica from satellite-derived temperature data. J. Climate, 17, 1569-1583, doi:10.1175/1520-0442(2004)017<1569: RCVIAF $>2.0 . \mathrm{CO} ; 2$.

$\longrightarrow,-$ T T. D. van Ommen, D. A. Dixon, P. A. Mayewski, J. M. Jones, and C. M. Bitz, 2006: Antarctic temperatures over the past two centuries from ice cores. Geophys. Res. Lett., 33, L16707, doi:10.1029/2006GL027057.

— C. Deser, and Y. Okumura, 2012a: An assessment and interpretation of the observed warming of West Antarctica in the austral spring. Climate Dyn., 38, 323-347, doi:10.1007/ s00382-010-0985-x.

— , Y. Okumura, and C. Deser, 2012b: Observed Antarctic interannual climate variability and tropical linkages. J. Climate, 25, 4048-4066, doi:10.1175/JCLI-D-11-00273.1.

Screen, J. A., and I. Simmonds, 2012: Half-century air temperature change above Antarctica: Observed trends and spatial reconstructions. J. Geophys. Res., 117, D16108, doi:10.1029/ 2012JD017885. 
Shepherd, A., and Coauthors, 2012: A reconciled estimate of icesheet mass balance. Science, 338, 1183-1189, doi:10.1126/ science. 1228102 .

Shuman, C. A., and C. R. Stearns, 2001: Decadal-length composite inland West Antarctic temperature records. J. Climate, 14, 1977-1988, doi:10.1175/1520-0442(2001)014<1977: DLCIWA $>2.0 . C O ; 2$.

Simmons, A. J., K. M. Willett, P. D. Jones, P. W. Thorne, and D. P. Dee, 2010: Low-frequency variations in surface atmospheric humidity, temperature, and precipitation: Inferences from reanalyses and monthly gridded observational data sets. J. Geophys. Res., 115, D01110, doi:10.1029/2009JD012442.

Stanton, T. P., and Coauthors, 2013: Channelized ice melting in the ocean boundary layer beneath Pine Island Glacier, Antarctica. Science, 341, 1236-1239, doi:10.1126/science.1239373.

Steig, E. J., D. P. Schneider, S. D. Rutherford, M. E. Mann, J. C. Comiso, and D. T. Shindell, 2009: Warming of the Antarctic ice-sheet surface since the 1957 International Geophysical Year. Nature, 457, 459-462, doi:10.1038/nature07669.

_ , and Coauthors, 2013: Recent climate and ice-sheet changes in West Antarctica compared with the past 2,000 years. Nat. Geosci., 6, 372-375, doi:10.1038/ngeo1778.

Tedesco, M., W. Abdalati, and H. J. Zwally, 2007: Persistent surface snowmelt over Antarctica (1987-2006) from $19.35 \mathrm{GHz}$ brightness temperatures. Geophys. Res. Lett., 34, L18504, doi:10.1029/2007GL031199.

Thomas, E. R., P. F. Dennis, T. J. Bracegirdle, and C. Franzke, 2009: Ice core evidence for significant 100-year regional warming on the Antarctic Peninsula. Geophys. Res. Lett., 36, L20704, doi:10.1029/2009GL040104.

_ - T. J. Bracegirdle, J. Turner, and E. W. Wolff, 2013: A 308 year record of climate variability in West Antarctica. Geophys. Res. Lett., 40, 5492-5496, doi:10.1002/2013GL057782.

Thompson, D. W. J., and J. M. Wallace, 2000: Annular modes in the extratropical circulation. Part I: Month-to-month variability. J. Climate, 13, 1000-1016, doi:10.1175/1520-0442(2000)013<1000: AMITEC $>2.0 . \mathrm{CO} ; 2$.

- and S. Solomon, 2002: Interpretation of recent Southern Hemisphere climate change. Science, 296, 895-899, doi:10.1126/ science.1069270.
_ J. M. Wallace, and G. C. Hegerl, 2000: Annular modes in the extratropical circulation. Part II: Trends. J. Climate, 13, 1018-1036, doi:10.1175/1520-0442(2000)013<1018:AMITEC >2.0.CO;2.

— S. Solomon, P. J. Kushner, M. H. England, K. M. Grise, and D. J. Karoly, 2011: Signatures of the Antarctic ozone hole in Southern Hemisphere surface climate change. Nat. Geosci., 4, 741-749, doi:10.1038/ngeo1296.

Turner, J., and Coauthors, 2004: The SCAR READER project: Toward a high-quality database of mean Antarctic meteorological observations. J. Climate, 17, 2890-2898, doi:10.1175/ 1520-0442(2004)017<2890:TSRPTA >2.0.CO;2.

- and Coauthors, 2005: Antarctic climate change during the last 50 years. Int. J. Climatol., 25, 279-294, doi:10.1002/joc.1130.

_ , and Coauthors, 2009: Non-annular atmospheric circulation change induced by stratospheric ozone depletion and its role in the recent increase of Antarctic sea ice extent. Geophys. Res. Lett., 36, L08502, doi:10.1029/2009GL037524.

Van den Broeke, M. R., and N. P. M. van Lipzig, 2004: Changes in Antarctic temperature, wind and precipitation in response to the Antarctic Oscillation. Ann. Glaciol., 39, 119-126, doi:10.3189/172756404781814654.

van Lipzig, N. P. M., G. J. Marshall, A. Orr, and J. C. King, 2008: The relationship between the Southern Hemisphere annular mode and Antarctic Peninsula summer temperatures: Analysis of a high-resolution model climatology. J. Climate, 21, 1649-1668, doi:10.1175/2007JCLI1695.1.

Vaughan, D. G., and Coauthors, 2003: Recent rapid regional climate warming on the Antarctic Peninsula. Climatic Change, 60, 243-274, doi:10.1023/A:1026021217991.

Zheng, F., J. Li, R. T. Clark, and H. C. Nnamchi, 2013: Simulation and projection of the Southern Hemisphere annular mode in CMIP5 models. J. Climate, 26, 9860-9879, doi:10.1175/ JCLI-D-13-00204.1.

Zhang, L., A. Kumar, and W. Wang, 2012: Influence of changes in observations on precipitation: A case study for the Climate Forecast System Reanalysis (CFSR). J. Geophys. Res., 117, D08105, doi:10.1029/2011JD017347. 